Pacific Northwest

National Laboratory

Gperated by Battelle for the

U.S. Department of Energy

\section{Feasibility Study of Using High- Temperature Raman Spectroscopy for On-Line Monitoring and Product Control of the Glass Vitrification Process}

\section{RECEIVED \\ FEB 17 1999 \\ OST!}

December 1998

Prepared for the U.S. Department of Energy under Contract DE-AC06-76RLO 1830 


\section{DISCLAIMER}

Portions of this document may be illegible in electronic image products. Images are produced from the best available original document. 
Feasibility Study of Using HighTemperature Raman Spectroscopy for On-Line Monitoring and Product Control of the Glass Vitrification Process
H. $\mathrm{Li}$
Y. Su
G. F. Piepel
M. L. Elliott
C. F. Windisch, Jr.

December 1998

Prepared for the U.S. Department of Energy under Contract DE-AC06-76RLO 1830 


\section{Summary}

A pulse-gating Raman spectroscopy setup was developed in this project. The setup was capable of performing in-situ high-temperature Raman measurements for glasses at temperatures as high as $1412^{\circ} \mathrm{C}$. In the literature, high-temperature Raman measurements have only been performed on thin films of glass to minimize black-body radiation effects. The pulse-gating Raman setup allows making hightemperature measurements for bulk melts while effectively minimizing black-body radiation effects.

A good correlation was found between certain Raman characteristic parameters and glass melt temperature for sodium silicate glasses measured in this project. Comparisons were made between the high-temperature Raman data from this study and literature data. The results suggest that an optimization of the pulse-gating Raman setup is necessary to further improve data quality (i.e., to obtain data with a higher signal-to-noise ratio).

An UV confocal Raman microspectrometer with continuous wave laser excitation using a $325 \mathrm{~nm}$ excitation line was evaluated selectively using a transparent silicate glass and a deep-colored high-level waste glass in a bulk quantity. The data were successfully collected at temperatures as high as approximately $1500^{\circ} \mathrm{C}$. The results demonstrated that the UV excitation line can be used for high-temperature Raman measurements of molten glasses without black-body radiation interference from the melt for both transparent and deep-color glasses. Further studies are needed to select the best laser system that can be used to develop high-temperature Raman glass databases.

Statistical models, based on classical calibration and inverse calibration statistical methods, were developed using high-temperature data reported in the literature for sodium-alumino-silicate glasses. Within the composition and temperature regimes for which the models were developed, the predicted values for temperature or glass composition (in terms of $\mathrm{Al}_{2} \mathrm{O}_{3}$ for this literature data set) agree very well with actual values. $\mathrm{R}^{2}$ values for the classical and inverse calibration approaches were 0.951 and 0.982 , respectively, for melt temperature, and 0.990 and 0.995 , respectively, for glass composition $\left(\mathrm{Al}_{2} \mathrm{O}_{3}\right.$ concentration).

In conclusion, an on-line melt monitoring system (OMMS), composed of high-temperature Raman spectrometer and statistical models involving mathematical functions of Raman parameters, melt temperature, and melt composition, is shown by the results of this study to be feasible for on-line glass process control. The combination of an improved high-temperature Raman spectroscopy technology and reliable statistical models is envisioned to have potential applications for next-generation, integrated on-line process control systems for the commercial glass industry and radioactive waste glass vitrification facilities. 


\section{Acknowledgments}

The authors wish to acknowledge G. J. Exarhos and S. K. Sharma (currently affiliated with the University of Hawaii) for providing technical assistance during the development of the pulse-gating Raman setup and K. H. Jarman for providing technical input on statistical modeling. We are grateful to Renishaw Inc. for performing high-temperature UV Raman testing on silicate and borosilicate glasses. The authors are grateful to J. M. Perez, J. L. Buelt, W. C. Weimer, and J. L. Sealock for reviewing and supporting our innovative idea and proposal to study the feasibility of using on-line high-temperature Raman spectroscopic technique for glass processing control. Technical review of this report was provided by K. H. Jarman. Editorial review of this report was provided by R. E. Schrempf. 


\section{Contents}

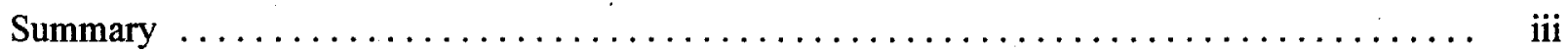

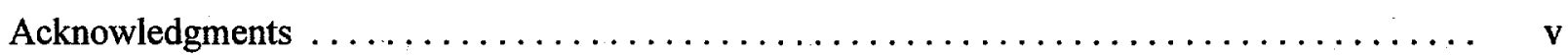

Abbreviations and Acronyms $\ldots \ldots \ldots \ldots \ldots \ldots \ldots \ldots \ldots \ldots \ldots \ldots \ldots \ldots \ldots \ldots \ldots \ldots$

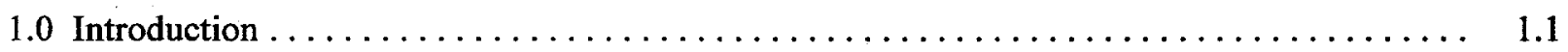

2.0 Research Methodology $\ldots \ldots \ldots \ldots \ldots \ldots \ldots \ldots \ldots \ldots \ldots \ldots \ldots \ldots \ldots \ldots \ldots \ldots \ldots \ldots \ldots .1$

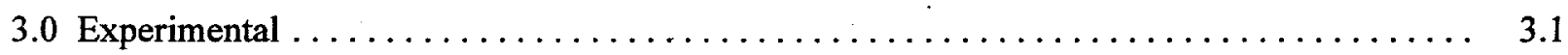

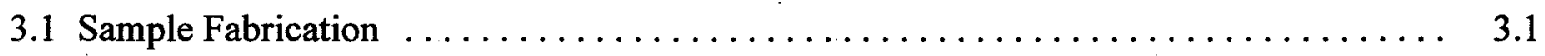

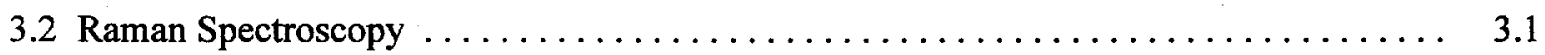

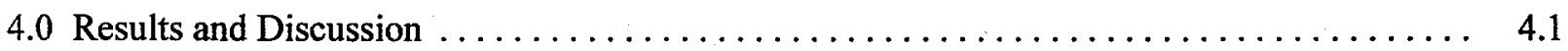

4.1 Temperature Effects on the Raman Spectra and Corrections $\ldots \ldots \ldots \ldots \ldots \ldots \ldots .1$

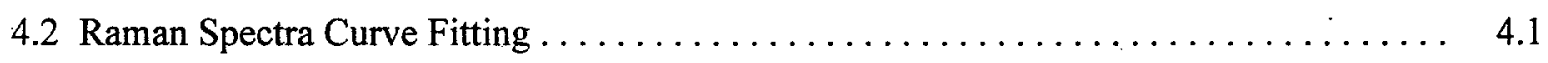

4.3 Factors Influencing High-Temperature Raman Measurements $\ldots \ldots \ldots \ldots \ldots \ldots$

4.4 Effects of the Laser excitation Lines on High-Temperature Raman Measurements $\ldots \ldots$

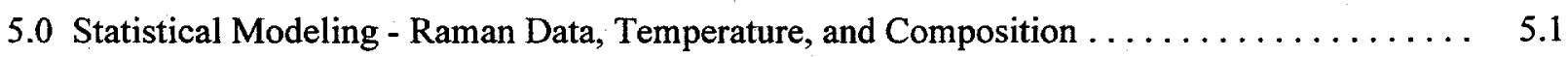

5.1 PNNL Sodium-Silicate Glass Data $\ldots \ldots \ldots \ldots \ldots \ldots \ldots \ldots \ldots \ldots \ldots \ldots \ldots \ldots \ldots \ldots \ldots \ldots \ldots$

5.2 Mysen and Frantz Sodium-Alumino-Silicate Glass Data $\ldots \ldots \ldots \ldots \ldots \ldots \ldots \ldots .1$

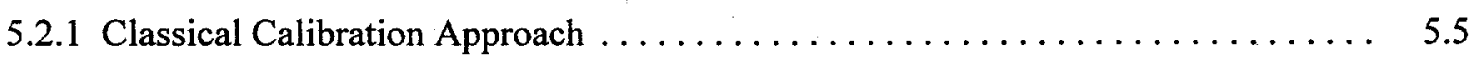

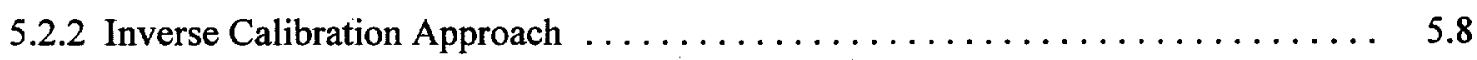

5.3 Comments on Statistical Multivariate Calibration $\ldots \ldots \ldots \ldots \ldots \ldots \ldots \ldots \ldots .14$

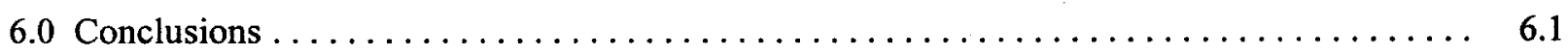

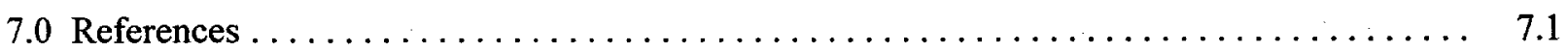

Appendix A - Statistical Multivariate Calibration $\ldots \ldots \ldots \ldots \ldots \ldots \ldots \ldots \ldots \ldots \ldots \ldots \ldots$ 
Appendix B - Plots of PNNL Pulse-Gating Raman Measurement Results $\ldots \ldots \ldots \ldots \ldots \ldots \ldots$

Appendix C - Plots of Mysen and Frantz Raman Data Used in Modeling $\ldots \ldots \ldots \ldots \ldots \ldots$ C.1 


\section{Figures}

1.1 A Schematic Illustration of the OMMS Concept $\ldots \ldots \ldots \ldots \ldots \ldots \ldots \ldots \ldots \ldots \ldots$

3.1 Experimental Setup for Performing Raman Spectroscopy on High-Temperature Glass Melts Using the Pulse-Gating Approach $\ldots \ldots \ldots \ldots \ldots \ldots \ldots \ldots \ldots \ldots \ldots \ldots \ldots \ldots \ldots \ldots \ldots \ldots .2$

3.2 Comparison of High-Temperature Raman Spectra of the OMMS-9801 Glass Using Continuous Wave Excitation and Pulse-Gating Showing that Black-Body Emission Interference is Essentially Eliminated Using the Pulse-Gating Approach . . . . . . . .

4.1 High-Temperature Raman Spectra of the OMMS-9801 Glass with and without Temperature Correction

4.2 Curve Fitting of the Measured High-Temperature Raman Spectrum for the OMMS-9801

Glass at $975^{\circ} \mathrm{C}$

4.3 Temperature Dependency of $Q^{i}$ Distribution Determined Using Pulse-Gating Raman Setup for the OMMS-9801 Glass

4.4 High-Temperature Raman Spectra of the OMMS-9802 Glass Collected Using Renishaw UV Confocal Raman Microspectrometer with a Laser Excitation Line of $325 \mathrm{~nm}$

4.5 High-Temperature Raman Spectra of the OMMS-9802 Glass Collected Using Pulse-Gating Raman Setup with a Laser Excitation Line of $523 \mathrm{~nm} . \ldots \ldots \ldots \ldots \ldots$

4.6 High-Temperature Raman Spectra of the REF 6 Glass Collected Using the Renishaw UV Confocal Raman Microspectrometer with a Laser Excitation Line of $325 \mathrm{~nm}$. . . . . .

5.1 Predicted Versus Measured Plot for Classical Calibration Equations Relating Glass Melt Temperature to Raman Parameters . . . . . . . . . . . . . . . . . . . . . . .

5.2 Predicted Versus Measured Plot for Classical Calibration Equations Relating Glass Composition to Raman Parameters

5.3 Predicted Versus Measured Plot for Inverse Calibration Equations Relating Glass Melt Temperature to Raman Parameters . . . . . . . . . . . . . . . . . . . . . . . .

5.4 Predicted Versus Measured Plot for Inverse Calibration Equations Relating Glass Composition to Raman Parameters 


\section{Tables}

3.1 Target Compositions of Glasses and Glass Melting History $\ldots \ldots \ldots \ldots \ldots \ldots \ldots \ldots \ldots$

4.1 Raman Data for OMMS-9801, -9802, and -9803 Sodium Silicate Glasses . . . . . . . . 4.4

4.2 Target Composition of the WVDP Nonradioactive REF 6 Glass $\ldots \ldots \ldots \ldots \ldots$

5.1 Notation and Various Representations of Composition for Five Glasses Studied by

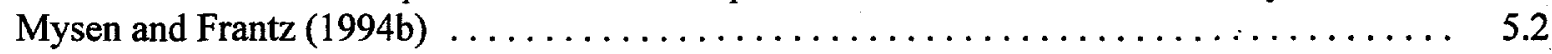

5.2 Raman Data for Five Glasses Studied by Mysen and Frantz (1994b) . . . . . . . . 5.3

5.3 Results of Fitting Classical Calibration Equations to Mysen and Frantz Data (1994b) . . . . 5.6

5.4 Classical and Inverse Calibration Results for Mysen and Frantz Data (1994b) . . . . . . 5.9

5.5 Fitted Inverse Calibration Equations for Mysen and Frantz Data (1994b) $\ldots \ldots \ldots \ldots .12$ 


\section{Abbreviations and Acronyms}

\begin{tabular}{ll} 
ASTM & American Society for Testing and Materials \\
CCD & charge-coupled detector \\
CW & continuous wave \\
DOE & U.S. Department of Energy \\
FWHM & full width at half maximum \\
HLW & high-level waste \\
LDRD & Laboratory Directed Research Development \\
NDA & non-disclosure agreement \\
OMMS & on-line melt monitoring system \\
PCT & product consistency test \\
PNNL & Pacific Northwest National Laboratory \\
RMSNoise & root mean square noise \\
RSM & research-scale melter \\
UV & ultra-violet \\
WVDP & West Valley Demonstration Project \\
\hline
\end{tabular}




\subsection{Introduction}

Currently operating vitrification plants for commercial and radioactive high-level waste (HLW) glasses rely on process control of feed materials before they enter the melter and sampling glass after it exists from the melter to control the vitrification process and assure product quality. While process control upstream of the melter is an essential aspect of the vitrification process, it has the shortcoming of being based on compositions of the feed materials and not on the composition of the melt in the melter. Similarly, sampling glass after it exits from the melter is an inarguable way to demonstrate product quality. However, sampling glasses after they have exited the melter does not allow the problem to be detected and fixed on-line. For radioactive HLW glasses, samples and tests are also very expensive and require personnel exposure to radiation. An on-line analysis method would allow the glass composition to be adjusted prior to pouring, such that product rejection or recycle would not be necessary.

For HLW glasses, it is anticipated that the viscosity of glass in the melter will fluctuate about the targeted level, which can be predicted by an existing model for melt viscosity as a function of glass composition (Hrma, Piepel, et al. 1994). However, this model must be applied to estimates of glass composition based on estimates of feed composition obtained by pre-melter sampling and analysis prior to and during the vitrification process. Differences in feed and melt compositions are typically not accounted for in this process. Neither are composition variations and other variations within the melter. Therefore, an on-line monitoring system that provides real-time information about the melt would have several advantages.

Vitrified HLW glass must meet several waste form acceptance criteria specified by DOE (US DOE, 1996). The "product consistency" criterion requires that the vitrified HLW form have normalized sodium, boron, and lithium releases less than specified limits using the ASTM C1285-94 procedure (ASTM, 1994) for 7-day product consistency test (PCT). Although glass compositions are formulated to be durable and pass the 7-day PCT, this must be verified during and after the vitrification process. Chemical composition analysis of the final waste form and 7-day PCT verification can be used to meet the criteria, yet these are time consuming and costly. While some levels of pre-melter process monitoring and control and post-melter verification will always be needed, it may be possible to minimize these needs and further enhance the vitrification process and product quality by directly monitoring the glass melt.

For commercial glasses, bubble dissolution and removal in the glass refining stage are very critical to the final product quality. A current industry practice is to refine molten glass for much longer time than is necessary to reduce and eliminate bubbles in the melt, thus ensuring product quality. This practice results in more energy consumption, higher emissions, and shorter melter life per tonnage of glass produced. Bubbles in the melt for transparent glasses can be detected using Raman spectroscopy, and this information can be used to control the glass refining process and reduce the overall costs of glass production. 
Methods for directly monitoring and controlling processing conditions and melt quality in the melter are needed to address these shortcomings. This project studied the feasibility of using an on-line monitoring system (OMMS) that provides quantitative real-time information on the melt for vitrification process optimization and product quality control.

Raman spectroscopy has been widely and successfully applied to glass structure studies for more than 20 years (Brawer and White 1975, 1977; Furukawa and White 1981; Mysen et al. 1981, 1982; McMillan et al. 1982; Bunker et al. 1990). High temperature Raman spectroscopy has been developed to perform in-situ studies on the thermodynamics of molten glass structures at temperatures as high as $1669^{\circ} \mathrm{C}$ (Seifert et al. 1981; Mysen and Frantz 1993a, 1993b, 1994a, 1994b; Saniel et al. 1995). Glass melt viscosity and chemical durability depend on glass structure that is governed by the distributions of specific chemical groups of glass forming components such as $\mathrm{SiO}_{2}$ and $\mathrm{B}_{2} \mathrm{O}_{3}$. A more polymerized melt with a higher concentration of bridging oxygens (BOs), $\mathrm{Si}-\mathrm{O}-\mathrm{Si}$, will result in higher melt viscosity at a given temperature and higher chemical durability. The polymerization of the glass network as a function of glass composition for simple systems can be monitored using Raman spectroscopy. It has been also well established that the change in viscosity of a glass system with a fixed composition as a function of temperature results from the redistribution of the glass-forming structural groups in the melt. Therefore, in principle, the thermodynamics of molten glasses can be studied using high-temperature Raman spectroscopy and physical properties, such as melt viscosity and durability. Then, melt compositions can be modeled by statistically analyzing spectra characteristics obtained from in-situ high-temperature Raman measurements.

Previously reported high-temperature Raman studies (Seifert et al. 1981; Mysen and Frantz 1993, 1994a, 1994b; Saniel et al. 1995) are limited to binary and pseudo-binary silicate based glass systems. To apply Raman spectroscopy for on-line measurement of molten glass for commercial and HLW glass processing control, high-temperature Raman spectroscopy databases must be developed for multicomponent silicate and borosilicate glasses for both commercial and HLW glasses.

The objective of this research is to provide proof-of-principle that an on-line melt monitoring system (OMMS) can be developed for process and quality control of vitrification process systems. The proofof-principle will be provided by conducting Raman spectroscopic measurements on silicate and borosilicate glasses, and applying statistical modeling to show that high-temperature Raman spectroscopy data can be quantitatively correlated to important glass processing parameters. ${ }^{(a)}$

The concept of the OMMS is schematically illustrated in Figure 1.1. An incoming melter feed (e.g., waste and glass forming additives for HLW glasses) is heated in a Joule-heated melter. Batch free time can be determined by a high-temperature Raman detector that monitors the molten glass at different positions: 1) below the interface between the batch pile and the melt, 2) the middle of the melter, and

(a) An invention report entitled "On-line Melt Monitoring System (OMMS) High-Temperature Raman Spectroscopy/Statistical Glass Structure-Property Models" was filed and recorded at the PNNL with the invention report number E-1640 on November 19, 1997. 


\section{OMMS Function : Real-Time Process and Quality Control}

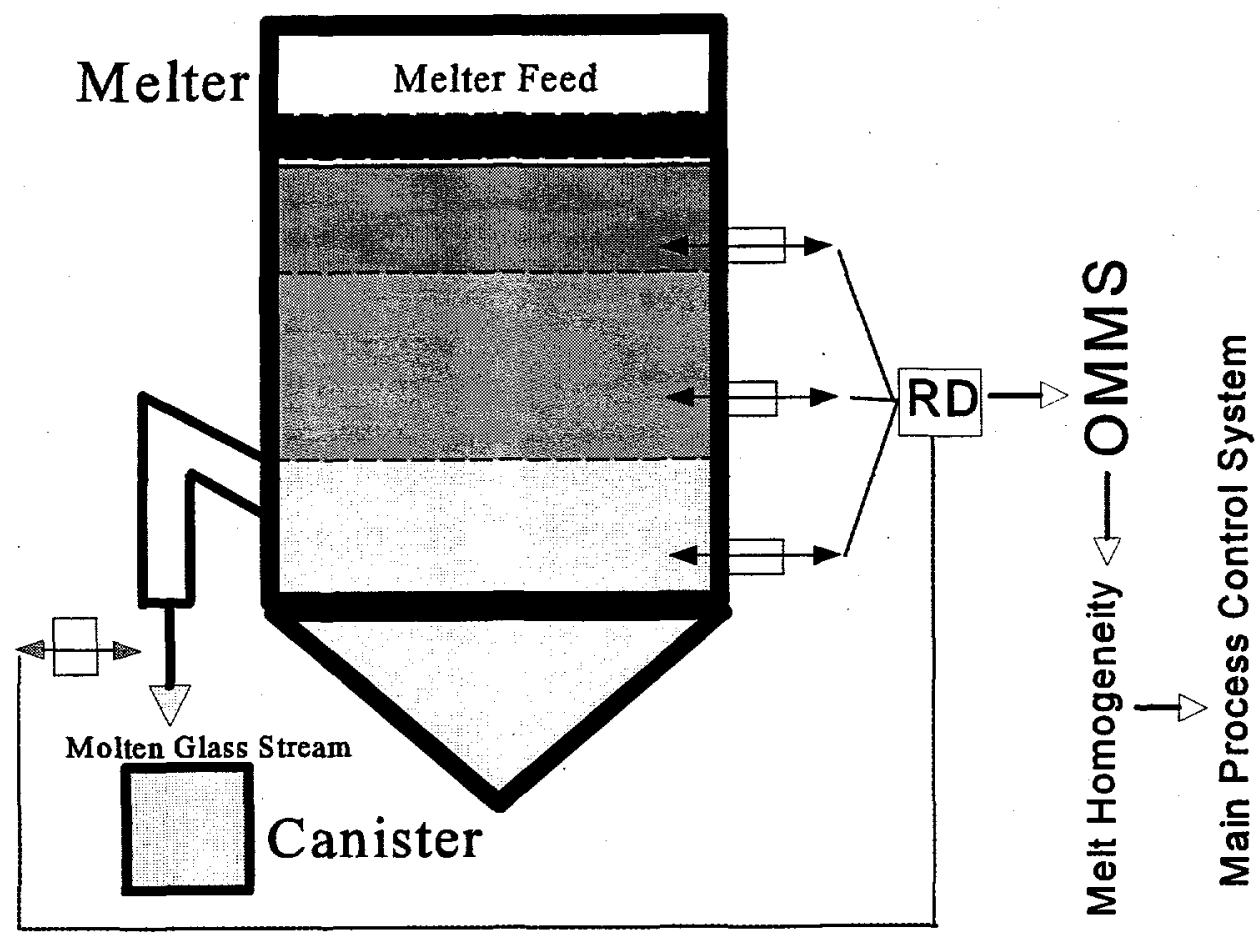

Figure 1.1. A Schematic Illustration of the OMMS Concept (RD - Raman detector)

3) the position near the melt pouring port. The time to achieve homogenous molten glass can be determined by analyzing the Raman data collected from the three positions and by comparing the data with a database stored in the OMMS. At the same time, the melt viscosities, compositions of the major glass constituents, and glass quality (being translated to glass durability for waste glasses) can be quantitatively determined using the database and models in the OMMS. For additional glass quality verification, it is also possible to monitor a glass product by collecting Raman data on a melt stream that is pouring out of the melter. Doing so would eliminate the need for collecting pour stream samples and performing chemical analyses and property measurements. 


\subsection{Research Methodology}

Three stages of the proposed study under the Laboratory Direct Research Development (LDRD) project are envisioned. In the Phase I work discussed in this report, the study focused on simple silicate melts and various high-temperature Raman spectroscopic configurations. The Phase I work examined whether glass melts in bulk quantities (rather than thin films of glass melt as reported in the literature) can be studied. Phase I also involved developing statistical models of high-temperature Raman spectra characteristics (or parameters) as a function of composition and temperature for simple silicate systems using data obtained from this study and the literature. Complex borosilicate glasses such as HLW glasses were not studied in Phase I. However, initial testing was performed on a non-radioactive HLW glass, which provided a certain degree of confidence for the coming Phase II study. In addition, a preliminary evaluation of laser excitation lines for the Raman measurements was made with the assistance of Renishaw, Inc. ${ }^{\text {(a) }}$ The evaluation is important for selecting the best laser excitation line that will give high-quality Raman scattering signals from both transparent and dark-colored glasses.

In Phase II, efforts will be devoted to database development. High-temperature Raman data will be collected over a wide range of glass compositions as a function of temperature. Both silicate and borosilicate glasses will be covered. Based on the data from Phase II, statistical models will be fully developed over the composition regimes for particular glass systems. In Phase II, the models will be tested independently using data not used in model development. To ensure the quality of the Raman data, the optimized Raman setup (including the laser excitation line) will be determined in early work of Phase II.

In Phase III, the research will be devoted to Raman hardware development to complete the OMMS technology development. At this stage, it is envisioned that research will be collaborative with a private sector company specializing in Raman technology. Depending on the maturity of hardware development, OMMS may be tested in-house at Pacific Northwest National Laboratory (PNNL) using the existing Research Scale Melter (RSM). Certain modifications on the RSM are required to adapt the Raman hardware.

(a) Renishaw, Inc. signed a Non-Disclosure Agreement (NDA) Form with Pacific Northwest National Laboratory on April 27, 1998. After signing the NDA, Renishaw, Inc. was asked by PNNL to provide technical assistance demonstrating in-situ high-temperature measurements of the West Valley Demonstration Project (WVDP) nonradioactive Reference 6 glass using Raman spectrometers manufactured by Renishaw, Inc. 


\subsection{Experimental}

The experimental work to fabricate sodium silicate glasses and make high-temperature Raman spectroscopy measurements on them is described in this section.

\subsection{Sample Fabrication}

Sodium silicate glasses, $\mathrm{xNa}_{2} \mathrm{O} \cdot(1-\mathrm{x}) \mathrm{SiO}_{2}$, were selected for the high-temperature Raman feasibility study. The compositions are summarized in Table 3.1. Batch materials using high purity regent grade $\mathrm{Na}_{2} \mathrm{CO}_{3}$ and $\mathrm{SiO}_{2}$, were mixed in an agate disk mill for five minutes. Depending on composition, the melting temperatures ranged from 1230 to $1280^{\circ} \mathrm{C}$. Each glass was melted using a Pt-10\% Rh crucible for one hour in a resistance-heated DELTECH ${ }^{\circledR}$ furnace and then quenched by pouring the melt onto a stainless steel plate. The quenched glass was ground in a tungsten carbide disk mill for five minutes, remelted for one hour, and then quenched by pouring the melt onto the stainless steel plate. The final glasses were transparent and free from any seeds or stones.

To prepare samples for Raman measurements, several broken pieces of glass were fused in a Pt- $10 \%$ Rh cup at about $1150^{\circ} \mathrm{C}$ for 3 minutes and then air quenched. Small amounts of bubbles were found in the samples.

\subsection{Raman Spectroscopy}

Raman spectra were acquired on high-temperature glass samples using three separate experimental setups. Two of the setups were abandoned because black-body emission limited the highest temperature at which Raman spectra could be obtained. The maximum temperature at which Raman spectra could be separated from the black-body emission background was about $900^{\circ} \mathrm{C}$. The first of the abandoned

Table 3.1 Target Compositions of Glasses and Glass Melting History

\begin{tabular}{|c|c|c|c|c|c|}
\hline \multirow[b]{2}{*}{ Glass ID } & \multicolumn{2}{|c|}{ Composition (wt\%) } & \multicolumn{2}{|c|}{ Composition (mol\%) } & \multirow{2}{*}{$\begin{array}{l}\text { Melting History } \\
\left({ }^{\circ} \mathrm{C} / \mathrm{h} / \text { cooling) }\right.\end{array}$} \\
\hline & $\mathrm{Na}_{2} \mathrm{O}$ & $\mathrm{SiO}_{2}$ & $\mathrm{Na}_{2} \mathrm{O}$ & $\mathrm{SiO}_{2}$ & \\
\hline OMMS-9801 & 36.32 & 63.68 & 35.6 & 64.4 & $\begin{array}{l}\text { 1200/1/quench } \\
1230 / 1 / \text { quench }\end{array}$ \\
\hline OMMS-9802 & 34.03 & 65.97 & 33.33 & 66.67 & $\begin{array}{l}\text { 1250/1/quench } \\
1280 / 1 / \text { quench }\end{array}$ \\
\hline OMMS-9803 & 38.73 & 61.27 & 38.00 & 62.00 & $\begin{array}{l}1200 / 1 / \text { quench } \\
1250 / 1 / \text { quench }\end{array}$ \\
\hline
\end{tabular}


approaches used a Spex 1877 triple Raman spectrometer equipped with a 1482 ET Micramate microscope, a Princeton Instruments LN/CCD detector (CCD stands for charge-coupled detector), and continuous wave $(\mathrm{CW})$ laser excitation using a Spectra Physics $164 \mathrm{Ar}^{+}$ion laser. Glass samples were heated in a specially designed microfurnace placed under the microscope objective. The second abandoned method used a forward scattering geometry through a larger furnace containing a sapphire cell. The third setup used a pulse-grating approach and was successful at reducing black-body emission interference to temperatures as high as $1414^{\circ} \mathrm{C}$.

A schematic of the pulse-gating setup is shown in Figure 3.1. The $532 \mathrm{~nm}$ line of a Spectra Physics Quanta Ray GCR pulsed Nd:YAG laser was used for excitation. Laser power was 0.13 Watts at the sample. Pulse frequency was $30 \mathrm{~Hz}$ and pulse width was $10 \mathrm{~ns}$. A Spex $270 \mathrm{M}$ single monochromater was used with an Princeton Instruments ICCD detector. The monochromater had a fixed position grating and a Kaiser Optics holographic notch filter was used to reduce Rayleigh scattering. The entrance slit of the detector was $100 \mu \mathrm{m}$. In these experiments, a single spectrum was the sum of several acquisitions over a $100 \mathrm{~s}$ interval, with each acquisition timed to the laser pulse. The timing was accomplished by using an output signal from the laser to trigger a gate pulse which activated the detector intensifier.

This strategy significantly reduced the black-body contribution to the signal as illustrated in Figure 3.2. Glass samples were contained in a small Pt crucible inside the same microfurnace used in first (abandoned) approach described above. A furnace cover with a quartz window minimized heat loss

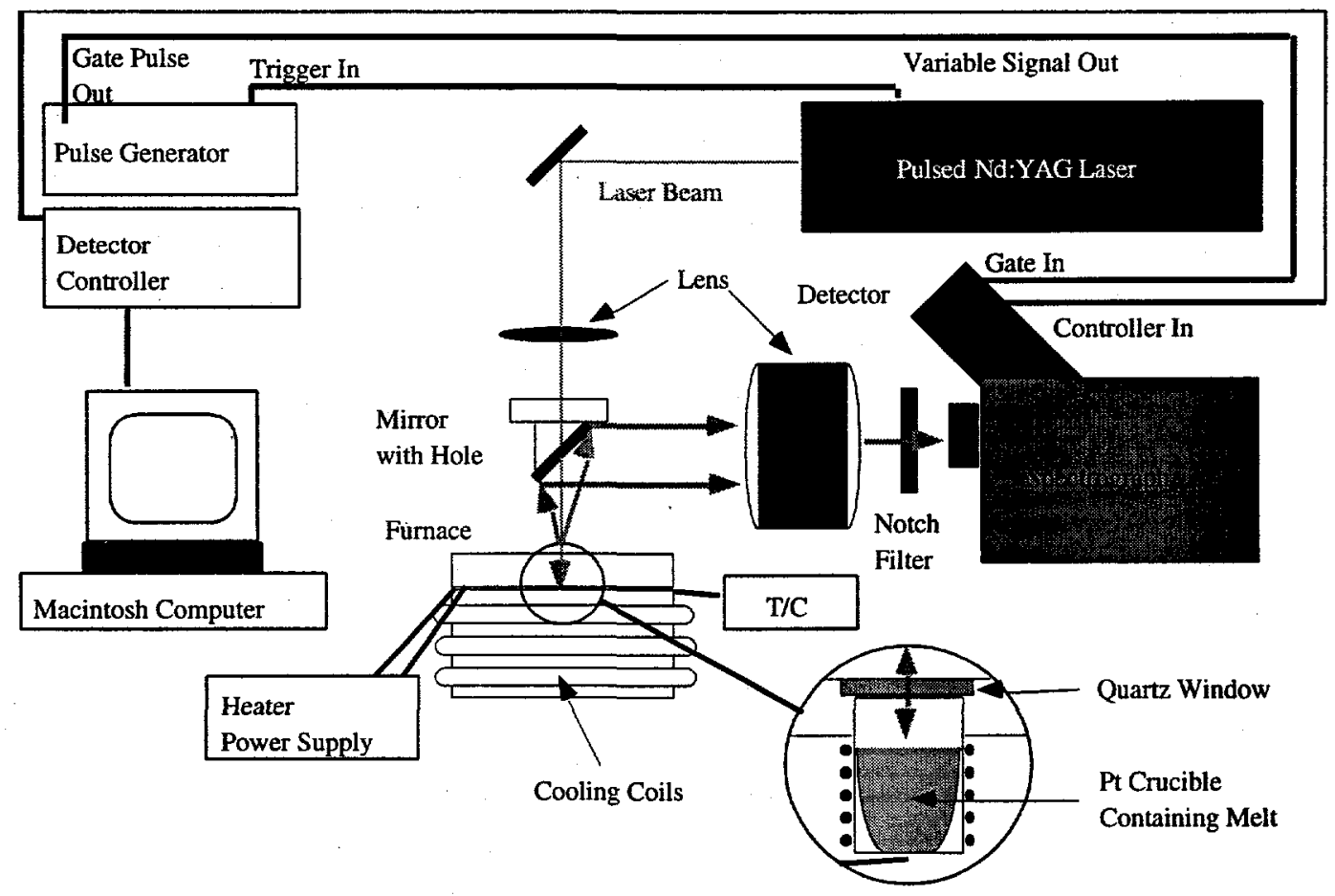

Figure 3.1. Experimental Setup for Performing Raman Spectroscopy on High-Temperature Glass Melts Using the Pulse-Gating Approach 


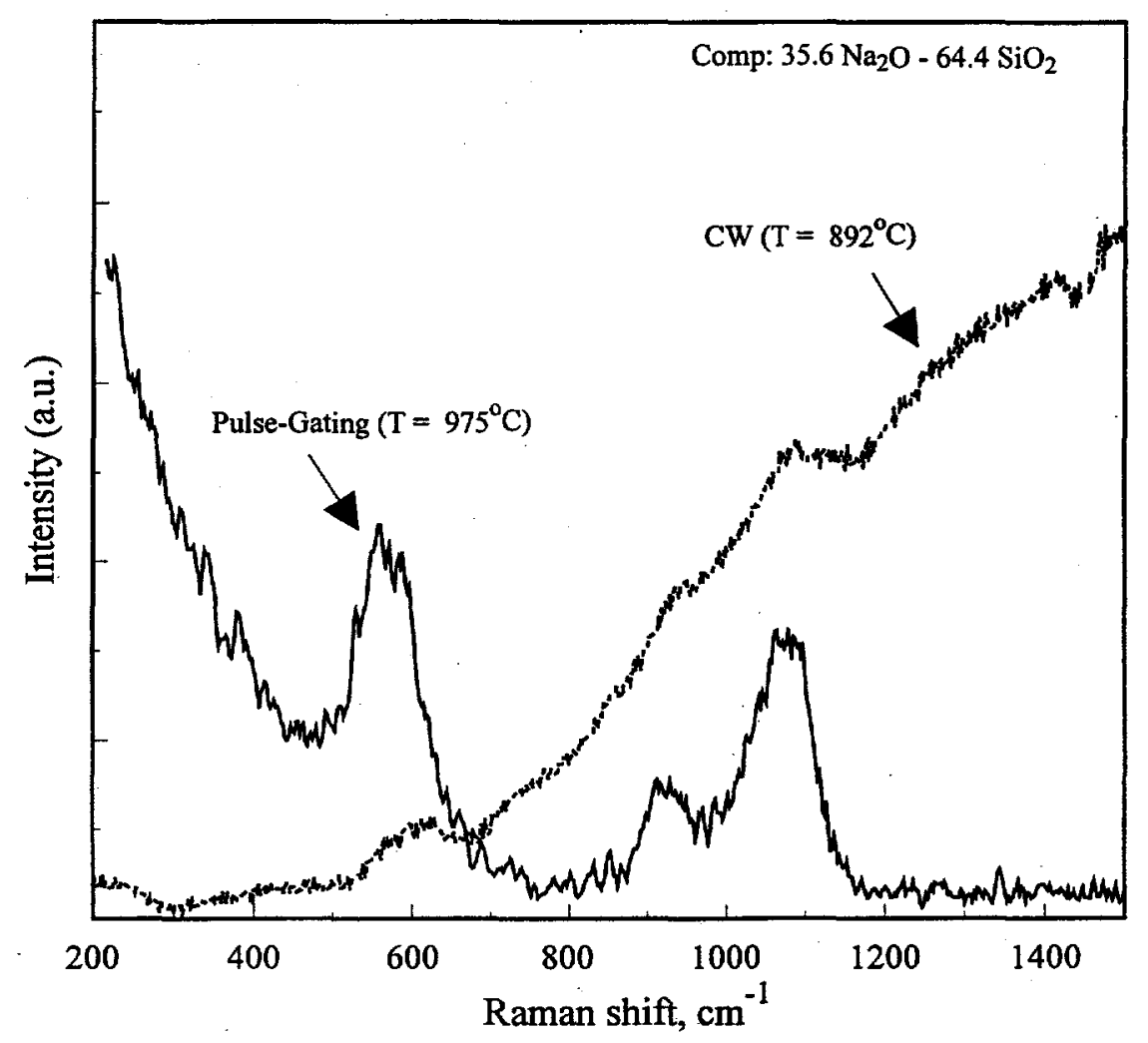

Figure 3.2. Comparison of High-Temperature Raman Spectra of the OMMS-9801 Glass Using Continuous Wave (CW) Excitation and Pulse-Gating Showing that Black-Body Emission Interference is Essentially Eliminated Using the Pulse-Gating Approach

and a thermocouple measured temperature directly under the Pt crucible. The setup used a backscattering configuration. Incident light was directed through a mirror with a hole in it, and scattered light was directed by the same mirror into the spectrograph. A single lens collimated the scattered light through the notch filter and into the spectrometer. Data acquisition was performed using a Macintosh computer and Princeton Instruments Kestralspec software. Curve fitting and further data analysis were accomplished with Grams/32 software (Galactic Industries Corp, Salem, NH). Raman spectra were obtained on glasses at temperatures between $25^{\circ} \mathrm{C}$ and $1414^{\circ} \mathrm{C}$. 


\subsection{Results and Discussion}

This section presents the results and discussion of the experimental work described in Section 3.

\subsection{Temperature Effects on the Raman Spectra and Corrections}

Increasing temperature affects Raman spectra in several ways distinct from changes in the relative peak intensities related to the distributions of the glass structure groups at equilibrium states. Therefore, these other temperature effects must be sorted out and, preferably, their contributions subtracted from the spectra. Perhaps the biggest single temperature interference is from black-body emission, which was discussed in Section 3.2. Another temperature effect that must be taken into account is the shift in the energy distribution that occurs at high temperatures, which is not related to the distribution of the glass structure groups. Bose-Einstein statistics require that the higher vibrational energy states will be more heavily populated at higher temperatures. This will result in a net loss of Stokes Raman intensities and an increase in anti-Stokes Raman intensities. Since this temperature effect will be greater at lower vibrational frequencies, the relative peak intensities can be strongly perturbed at higher temperatures. If uncorrected, peak ratios can be significantly in error particularly when a low frequency band is used in the calculation.

A common approach to correcting Raman spectra for temperature is described by Walrafen et al. (1986). This approach generates a "frequency reduced spectra" using the expression

$$
\begin{aligned}
I_{(\text {red })} & =\frac{v I_{(\text {meas })}}{(1+n)} \\
n & =\frac{1}{\left(e^{\frac{\text { hvc }}{k T}}-1\right)}
\end{aligned}
$$

where $I_{(\text {red })}$ and $I_{\text {(mea.s) }}$ are the reduced and measured Raman intensity, respectively. $(1+n)$ is the phonon Bose-Einstein (BE) factor, $v$ is the frequency, $T$ is the absolute temperature, $h$ is the Plank's constant, and $c$ is the velocity of light in a vacuum. Figure 4.1 illustrates the result of applying this correction to a selected spectrum for the OMMS- 9801 glass at $975^{\circ} \mathrm{C}$. Notice that the intensity of low frequency modes are more strongly affected by the correction than the high frequency modes. Unless noted otherwise, all spectra in this work were corrected for temperature using the above approach.

\subsection{Raman Spectra Curve Fitting}

The Raman spectra have been deconvoluted with the Grams/32 software (Galactic Industries Corp, Salem, NH). The curve fitting is based on the non-linear least squares algorithm described by Marquardt, known as the Levenberg-Marquardt method (Marquart 1963). The method is extremely 


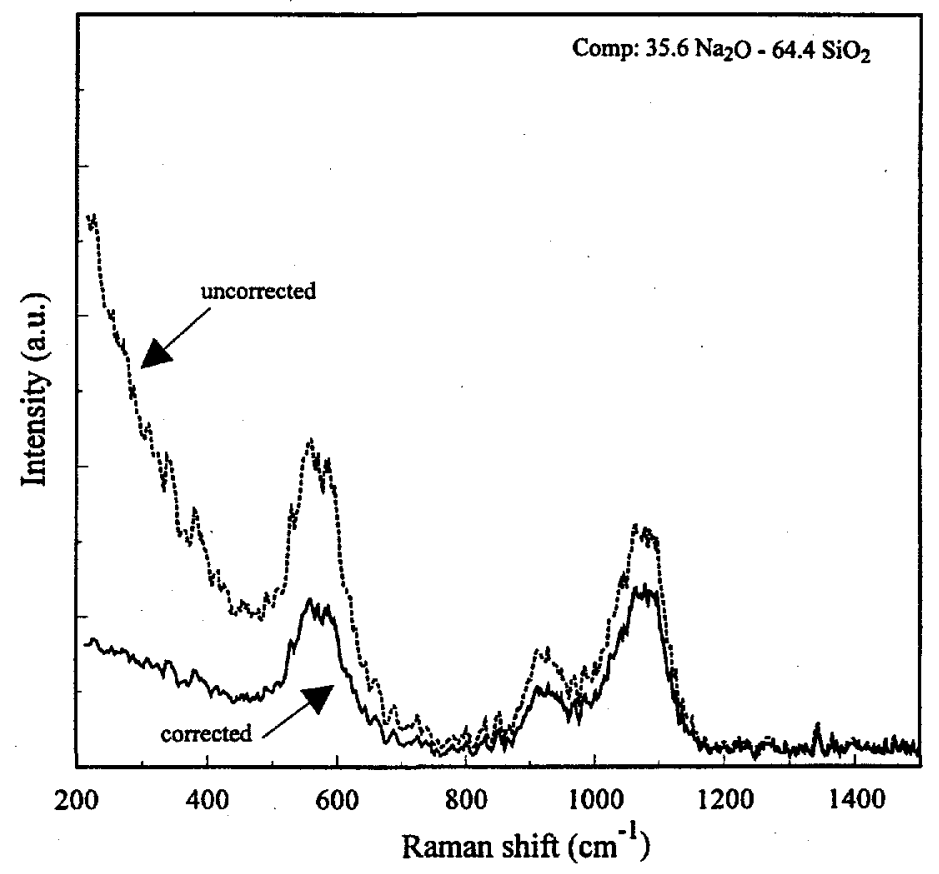

Figure 4.1. High-Temperature Raman Spectra of OMMS-9801

Glass with and without Temperature Correction

useful for fitting overlapping peaks, from which can be extracted peak positions, full widths at half maxima (FWHM), heights, and areas. However, the method is less useful for determining the exact number of peaks except, in an indirect fashion, by examining the residual error of the fit for different numbers of fitted peaks. Mysen et al. (1982) recommended fitting the spectra by minimizing $\chi^{2}$ values (described below) and by maximizing the randomness of the residuals. The number of peaks chosen is such that a further increase in the number of peaks does not improve either the residual distribution or the value of $\chi^{2}$.

In our study, the number of peaks for a given glass composition was fixed based on literature data for glasses with similar compositions (MacMillan 1984). It is assumed that the peak shape may be described by Gaussian functions:

$$
f(v)=\mathrm{He}^{-4 \ln 2\left(\frac{v-v_{0}}{\mathrm{w}}\right)^{2}}
$$

where $v$ is the Raman data position (frequency), $v_{o}$ is the peak position (frequency), $H$ is the peak height or intensity, and $\mathrm{W}$ is the FWHM. The initial approximate estimates of the peak parameters, e.g. $v_{0}, \mathrm{H}$, and $W$, are entered into the curve fit program (Grams/32). The program adjusts these starting values to obtain the best (minimum $\chi^{2}$ ) fit of the sum of the calculated peaks to that of the measured spectrum. The $\chi^{2}$ value is given by: 


$$
\chi^{2}=\frac{\sum_{i=1}^{n}\left(\frac{I_{i(\text { meas })}-I_{i(\text { cal })}}{\text { RMSNoise }}\right)^{2}}{(n-f)}
$$

where $I_{i(\text { meas })}$ and $I_{i(\text { cal })}$ are the measured and calculated Raman intensity values, respectively, for the i-th data point. The RMSNoise is the estimated root mean squared noise in the measured data over the fitted region of the Raman shift, obtained by subtracting a smooth of the data from the raw data. The variable $n$ is the number of data points in the fitted region and $f$ is the total number of peak and baseline function parameters estimated from the Raman data. Thus, $n-f$ is the number of "residual" degrees of freedom for the fit. The Levenberg-Marquardt algorithm interactively adjusts every parameter for each peak in an attempt to minimize the $\chi^{2}$ (sometimes called reduced chi-squared). As can be deduced from Eq. (4.3), $\chi^{2}$ is simply a weighted difference measure between the actual and measured data. The resulting fitted parameters (i.e. widths, heights, frequencies, and areas) serve as the basis for structural interpretation.

The curve-fitting results are given in Table 4.1. Included in Table 4.1 are the $\mathrm{Na}_{2} \mathrm{O}(\mathrm{mol} \%)$ value for each glass, the test temperature $\left({ }^{\circ} \mathrm{C}\right)$, and three fitted or determined Raman peak parameters for peaks at nominal frequencies (or wavenumbers, or Raman shift) of 950,1000 , and $1100 \mathrm{~cm}^{-1}$. The "peak frequency" and peak FWHM" parameters are direct results of the nonlinear least squares fitting process described above. The "peak proportional areas" are calculated from integrated peak areas, as described in a footnote of Table 4.1.

An example of the curve-fitting results using the OMMS-9801 melt at $975^{\circ} \mathrm{C}$ are shown in Figure 4.2. The structural interpretation of the curve-fitted spectra is based on the available vibrational spectroscopic data in the literature (McMillan 1984). The glass and melts can be viewed in terms of coexisting structure units that represent average number of nonbridging oxygens per tetrahedrally coordinated cation such as $\mathrm{Si}$. The structure groups in silicate systems are described conventionally in terms of $Q^{i}$, i.e., the distribution of $i$ nonbridging oxygens per glass forming cation, $\mathrm{Si}$, in the melt at a given temperature. For example, the OMMS-9801 glass has structural units with $2\left(Q^{2}\right), 1\left(Q^{3}\right)$, and $0\left(Q^{4}\right)$ nonbridging oxygens coexisting. The temperature dependence of $Q^{i}$ distributions is illustrated in Figure 4.3.

Modeling the distributions of the glass structure groups such as $Q^{\prime}$, provides insight on the thermodynamics of the melt structures as functions of temperature and composition. This successful application of high-temperature Raman spectroscopy on simple silicate systems as previously shown by literature data and further demonstrated by the data obtained from this project does not guarantee an equal return for more complicated glass systems such as multi-component silicate and borosilicate glass systems. Specifically, in order to calculate the $Q^{i}$ fractions, the composition of the glass must be known. However, our ultimate goal is to predict glass composition, temperature, and physical properties using Raman data, in which case the $Q^{i}$ fractions cannot be calculated. Therefore, a statistical approach to hightemperature Raman spectroscopy was used exclusively in this study to "calibrate" high-temperature Raman spectra to glass composition and temperature. This approach treats Raman spectra as a calibration problem, instead dealing with specific glass structure assignments that are subject to high 
Table 4.1 Raman Data for OMMS-9801, -9802, and -9803 Sodium Silicate Glasses

\begin{tabular}{|c|c|c|c|c|c|c|c|c|c|c|c|}
\hline \multirow[b]{2}{*}{ Glass } & \multirow[b]{2}{*}{$\begin{array}{c}\mathrm{Na}_{2} \mathrm{O} \\
(\mathrm{mol} \%)\end{array}$} & \multirow[b]{2}{*}{$\begin{array}{c}\text { Temp. } \\
\left({ }^{\circ} \mathrm{C}\right)\end{array}$} & \multicolumn{3}{|c|}{$\begin{array}{c}\text { Peak Freqency, } \\
\text { cm }^{-1(a)}\end{array}$} & \multicolumn{3}{|c|}{$\begin{array}{c}\text { Peak FWHM, } \\
\text { cm }^{-1(b)}\end{array}$} & \multicolumn{3}{|c|}{ Peak Proportional Area ${ }^{(c)}$} \\
\hline & & & 950 & 1000 & 1100 & 950 & 1000 & 1100 & 950 & 1000 & 1100 \\
\hline 301 & 35.60 & 824 & 927 & 975 & 1072 & 59 & 57 & 89 & .176718 & 0.067262 & 0.756020 \\
\hline 801 & 35.60 & 954 & 936 & 1003 & 1074 & 90 & 46 & 96 & 0.235010 & 0.060528 & 0.704462 \\
\hline 9801 & 35.60 & 975 & 924 & 995 & 1075 & 61 & 70 & 82 & 0.184268 & 0.128874 & 0.686858 \\
\hline 301 & 35.60 & 1225 & 918 & 988 & 1067 & 63 & 70 & 87 & 0.210494 & 0.115916 & 0.673590 \\
\hline 01 & 35.60 & 1281 & 933 & 998 & 1068 & 80 & 43 & 86 & 0.237057 & 0.052729 & 0.710214 \\
\hline 9801 & 35.60 & 1317 & 924 & 988 & 1068 & 77 & 70 & 94 & 0.219168 & 0.074837 & 0.705995 \\
\hline 801 & 35.60 & 1325 & 929 & 993 & 1065 & 73 & 33 & 83 & 0.260539 & 0.021334 & 0.718127 \\
\hline 301 & 35.60 & 1407 & 917 & 987 & 1061 & $\overline{73}$ & 28 & 109 & 0.234620 & 0.034489 & 0.730891 \\
\hline 801 & 35.60 & 1414 & 926 & 994 & 1065 & 87 & 33 & 90 & 0.274481 & 0.032943 & 0.692577 \\
\hline 802 & 33.33 & 878 & 958 & 1013 & 1075 & 80 & 24 & 91 & 0.221633 & 0.035559 & 0.742807 \\
\hline 9802 & 33.33 & 972 & 953 & 1010 & 1075 & 104 & 24 & 89 & 0.220703 & 0.035232 & 0.744064 \\
\hline 302 & 33.33 & 1003 & 946 & 1008 & 1075 & 88 & 35 & 99 & 0.200988 & 0.041532 & 0.757480 \\
\hline 802 & 33.33 & 1065 & 941 & 1004 & 1078 & 83 & 35 & 93 & 0.208658 & 0.037337 & 0.754005 \\
\hline 9802 & 33.33 & 1133 & 937 & 1001 & 1080 & 76 & 50 & 93 & 0.201042 & 0.064367 & 0.734591 \\
\hline 302 & 33.33 & 1149 & 935 & 1010 & 1083 & 79 & 55 & 89 & 0.223131 & 0.099618 & 0.677250 \\
\hline 9802 & 33.33 & 1205 & 935 & 1006 & 1081 & 87 & 49 & 93 & 0.231342 & 0.065905 & 0.702753 \\
\hline $803^{(\mathrm{d}, \mathrm{e})}$ & 38.00 & 1017 & 944 & $*(f)$ & 1069 & 95 & $*(t)$ & 64 & 0.382420 & $*(f)$ & 0.617580 \\
\hline 9803 & 38.00 & 1039 & 941 & * (f) & 1070 & 91 & $*(f)$ & 65 & 0.429432 & $\neq$ & 0.570568 \\
\hline 9803 & 38.00 & 1146 & 939 & *(f) & 1072 & 100 & $*(t)$ & 69 & 0.455540 & $*(n)$ & 0.544460 \\
\hline \multicolumn{12}{|c|}{$\begin{array}{l}\text { (a) Frequency (location) of fitted Gaussian peak with nominal frequency } 950,1000 \text {, or } 1100 \mathrm{~cm}^{-1} \text {. } \\
\text { (b) Full width at half maximum of fitted Gaussian peak with nominal frequency } 950,1000 \text {, or } \\
1100 \mathrm{~cm}^{-1} \text {. } \\
\text { (c) Proportional area of fitted Gaussian peak with nominal frequency } 950,1000 \text {, or } 1100 \text {. For } \\
\text { example, } \\
\text { (d) } \mathrm{a}_{950}=\mathrm{A}_{900} /\left(\mathrm{A}_{950}+\mathrm{A}_{1000}+\mathrm{A}_{1100}\right) \text {, where } \mathrm{A}_{\mathrm{i}} \text { is the integrated area of the i-th peak. } \\
\text { (e) High-temperature Raman measurements were also made at } 820 \text { and } 843^{\circ} \mathrm{C} \text {, but those } \\
\text { measurements were affected by crystallization and thus are not reported here. } \\
\text { (f) During the Raman measurements at these temperatures glass leakage was found, which resulted in } \\
\text { lower Raman intensity during the measurement. Hence, this data set is provided here for } \\
\text { information only. }\end{array}$} \\
\hline
\end{tabular}




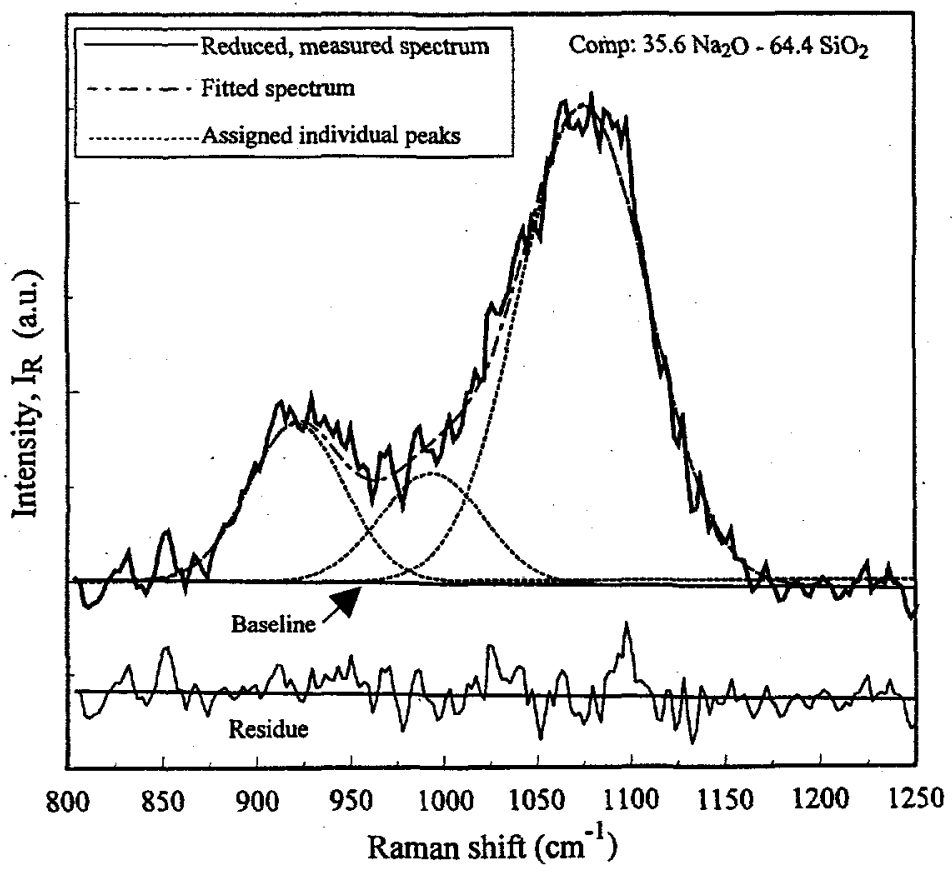

Figure 4.2. Curve Fitting of the Measured High-Temperature Raman Spectrum for the OMMS-9801 Glass at $975^{\circ} \mathrm{C}$

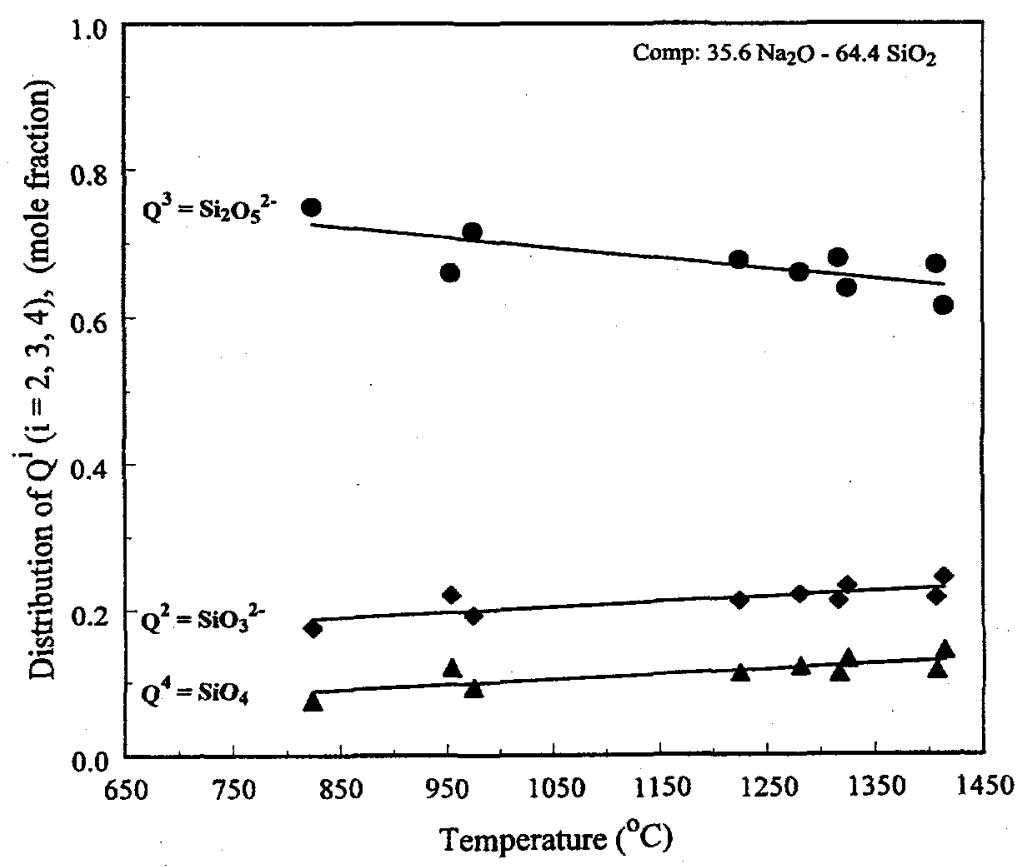

Figure 4.3. Temperature Dependency of $Q^{i}$ Distribution Determined Using Pulse-Gating Raman Setup for the OMMS-9801 Glass 
uncertainty and controversy for complex systems. The statistical calibration approach that relates Raman spectra of molten glasses to glass composition and temperature has never been attempted to the best of our knowledge from reviewing existing literature data.

\subsection{Factors Influencing High-Temperature Raman Measurements}

Three factors were found to affect the quality of the high-temperature pulse-gating Raman measurements in this study: 1) focusing the laser beam on the molten glass, 2) synchronizing the laser pulse time with the time of the CCD detector for collecting Raman scattering signals from the glass, and 3) glass crystallization. Optimizing laser focusing can minimize the noise-to-background ratio of the Raman spectra, whereas, precise time synchronizing using the pulse-gating technique can minimize the blackbody radiation effect on the background of the Raman spectra. In this study, the optimization of these two steps during the Raman measurements was attempted. Due to the limited resources of the current project and the requirements of manual adjustments, the final instrumental settings may not be optimized. More can be done to further improve Raman spectra quality in terms of instrument optical design, laser focusing, and the choice for the laser excitation line. Glass crystallization affects the interpretation of the Raman spectra. The signals are composed of a glassy phase with one composition and a crystalline phase with another and the compositions of both phases are changing with time at a given temperature. Therefore, it is important to collect Raman data at temperatures above the liquidus temperature to ensure that the Raman scattering signals from the glass are not composed of signals from any crystalline phases formed in the glass. Experimentally, it is sometimes necessary to check whether crystalline phases exist in the glass by other means, such as optical spectroscopy, if characteristic peaks of the Raman spectra for a given glass composition changes significantly, especially their peak widths becoming much narrower as the temperature increases in a low test temperature regime.

\subsection{Effects of the Laser Excitation Lines on High-Temperature Raman Measurements}

A preliminary evaluation of the effects of the laser excitation lines on high-temperature Raman spectroscopy measurements was performed with the assistance of Renishaw, Inc. An ultraviolet (UV) Raman spectrometer with a microscope attachment was used, and the laser excitation line had a wavelength of $325 \mathrm{~nm}$. Figure 4.4 shows the results of in situ UV confocal Raman measurements of the OMMS-9802 glass. The first data set was collected for the melt equilibrated at approximately $1500^{\circ} \mathrm{C}^{(a)}$ and the other data sets were collected for the same melt after being cooled from $1500^{\circ} \mathrm{C}$ and equilibrated at lower temperatures. Because of the temperature uncertainty of the hot stage, the Raman spectra were not corrected for the temperature effect. Figure 4.5 shows the high-temperature reduced Raman spectra of the OMMS-9802 glass, which were collected using the PNNL pulse-gating Raman setup with an

(a) The hot stage used for the high-temperature UV Raman measurements was not calibrated for temperature, and the change of hot stage temperature was controlled by varying the hot stage current input. Therefore, only maximum test temperature, approximately $1500^{\circ} \mathrm{C}$, was estimated judging from a white, bright color of the crucible in which the molten glass was held. 


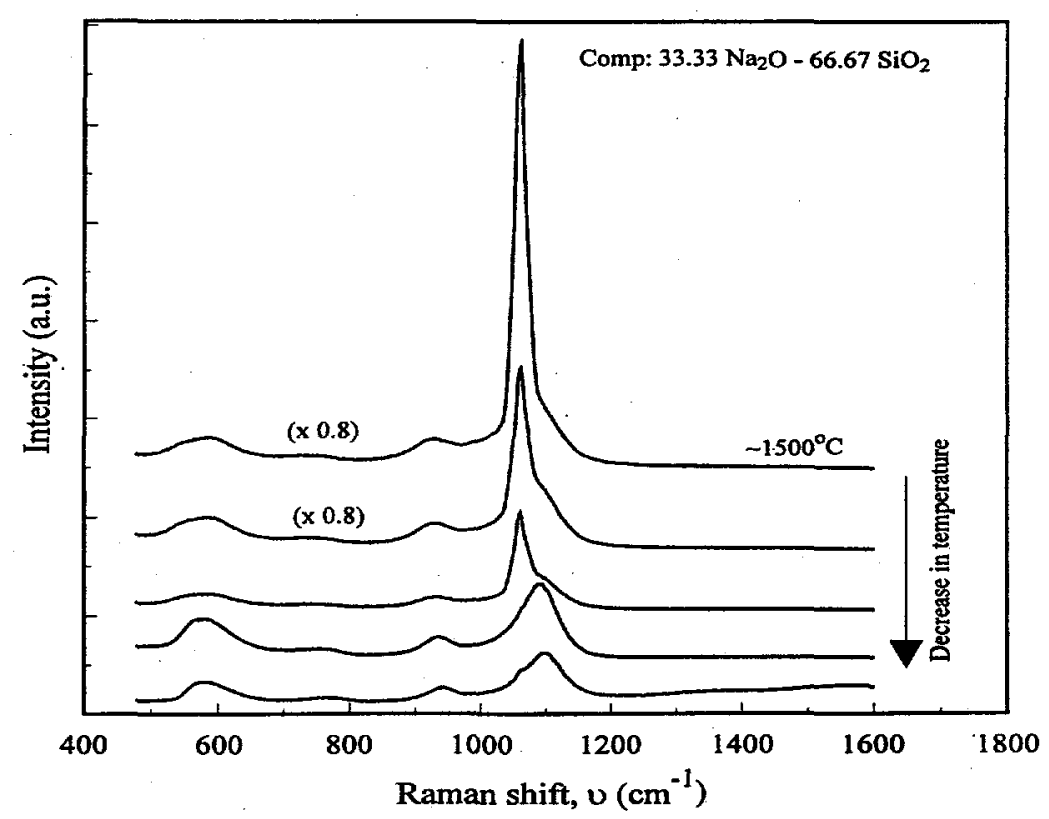

Figure 4.4. High-temperature Raman Spectra of the OMMS-9802 Glass Collected Using the Renishaw UV Confocal Raman Microspectrometer with a Laser Excitation Line of $325 \mathrm{~nm}$

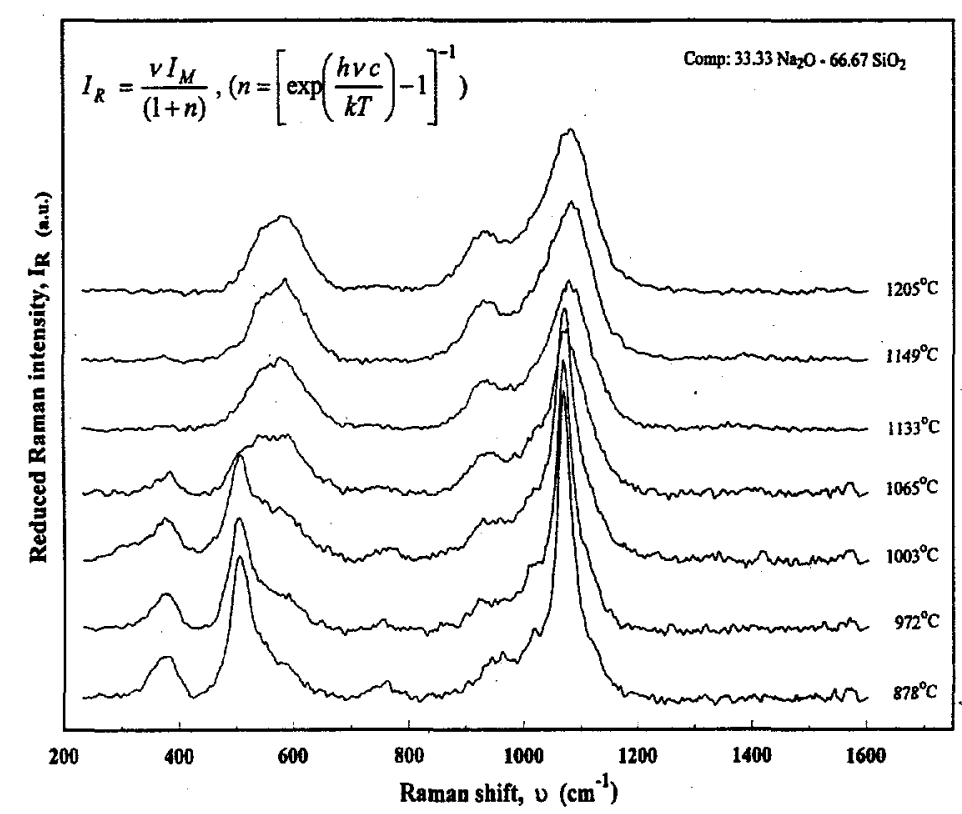

Figure 4.5. High-temperature Raman Spectra of the OMMS-9802 Glass Collected Using Pulse-Gating Raman Setup with a Laser of $523 \mathrm{~nm}$ 
excitation line of $523 \mathrm{~nm}$. Raman spectrum temperature correction can change the spectrum shape; the number of scattering peaks, however, are not changed. Hence, spectra from Figure 4.4 and 4.5 can be compared for the effect of overall instrumental differences on Raman scattering signals of the OMMS9802 glass (i.e., $325 \mathrm{~nm}$ excitation line versus $523 \mathrm{~nm}$ line, and continuos wave method versus pulsegating method).

Over the Raman shift from 400 to $1600 \mathrm{~cm}^{-1}$, the UV Raman measurements using the $325 \mathrm{~nm}$ line by the continuos wave method are shown to be not affected by black-body radiation. The same conclusion also can be drawn from the data collected using the $523 \mathrm{~nm}$ line by the pulse-gating method. The differences in the shapes of the Raman spectra collected by using these two methods are evident. There appears to be a systematic redistribution of peak intensity or area between the $950 \mathrm{~cm}^{-1}$ peak and the $1100 \mathrm{~cm}^{-1}$ peak as a function of temperature for the data sets collected by UV Raman. On the other hand, the intensity changes of the $1050 \mathrm{~cm}^{-1}$ peak in the spectra collected using pulse-gating method (cf. Figure 4.5) are less prominent. ${ }^{(a)}$ One possible explanation is that the test temperatures of the pulsegating Raman measurements were not high enough to see those significant peak redistributions. Crystallization may be another possibility for the significant changes in the $1050 \mathrm{~cm}^{-1}$ peak intensity as a function temperature in the UV Raman spectra. ${ }^{(b)}$ However, it is difficult to explain how the crystals redissolved in the melt at lower temperatures. To our knowledge, this is the first set of the hightemperature UV Raman data are ever collected for molten glass. Further evaluation on the hightemperature UV Raman spectroscopy of molten glasses is required to confirm whether the significant redistributions among the silicate structural groups occur or the observed phenomenon is a result of glass crystallization.

Despite of an uncertainty on the $1050 \mathrm{~cm}^{-1}$ peak intensity change with temperature, the above evaluation on the Raman instrument setup for high-temperature glass measurement suggests that it is feasible to use $325 \mathrm{~nm}$ UV confocal Raman microscope to collect high-temperature Raman data for binary silicate glasses.

To assess the application of the UV confocal Raman microspectrometer to different glass systems, especially high-level waste glasses that are composed of several transition metals, WVDP (West Valley Demonstration Project) standard reference glass (non-radioactive composition), REF 6, was used for evaluation. The composition of the REF 6 glass is shown in Table 4.2. Figure 4.6 shows the hightemperature UV Raman spectra of the REF 6 glass, where the data were collected at approximately $1500^{\circ} \mathrm{C}$ or below. The results show the $1050 \mathrm{~cm}^{-1}$ Raman peak characteristics (intensity and peak area) change with temperature, especially at higher temperatures. Also, several peaks occurred at different temperatures and different peak positions. These peaks are much sharper (in terms of full width at half maximum, FWHM) compared to the $1050 \mathrm{~cm}^{-1}$ Raman peak at each given temperature. These results suggest possible crystallization of different phases in the REF 6 glass at different temperatures, but most likely they are spikes. Once again, this is the first data set that is collected at high-temperature using UV

(a) The high-intensity peaks at lower temperatures ( 878 and 972 and possibly $1003^{\circ} \mathrm{C}$ ) of the pulse-gating Raman measurements were much sharper than those at higher temperatures as a result of glass crystallization.

(b) The crystallization of the glass at higher temperatures during UV Raman measurements may result from the loss of sodium from the melt at $1500^{\circ} \mathrm{C}$. 
Table 4.2. Target Composition of the WVDP Nonradioactive REF 6 Glass

\begin{tabular}{|c|c|c|c|}
\hline Oxide & wt\% & Oxide & wt\% \\
\hline $\mathrm{Al}_{2} \mathrm{O}_{3}$ & 6.26 & $\mathrm{MnO}$ & 0.86 \\
\hline $\mathrm{B}_{2} \mathrm{O}_{3}$ & 13.45 & $\mathrm{Na}_{2} \mathrm{O}$ & 8.35 \\
\hline $\mathrm{BaO}$ & 0.27 & $\mathrm{NiO}$ & 0.26 \\
\hline $\mathrm{CaO}$ & 0.50 & $\mathrm{P}_{2} \mathrm{O}_{5}$ & 1.25 \\
\hline $\mathrm{Ce}_{2} \mathrm{O}_{3}$ & 0.32 & $\mathrm{SO}_{3}$ & 0.24 \\
\hline $\mathrm{Cr}_{2} \mathrm{O}_{3}$ & 0.15 & $\mathrm{SiO}_{2}$ & 42.77 \\
\hline $\mathrm{Fe}_{2} \mathrm{O}_{3}$ & 12.55 & $\mathrm{SrO}$ & 0.26 \\
\hline $\mathrm{K}_{2} \mathrm{O}$ & 5.22 & $\mathrm{TiO}_{2}$ & 0.83 \\
\hline $\mathrm{Li}_{2} \mathrm{O}$ & 3.87 & $\mathrm{ZnO}$ & 0.27 \\
\hline $\mathrm{MgO}$ & 0.93 & $\mathrm{ZrO}$ & 1.38 \\
\hline
\end{tabular}

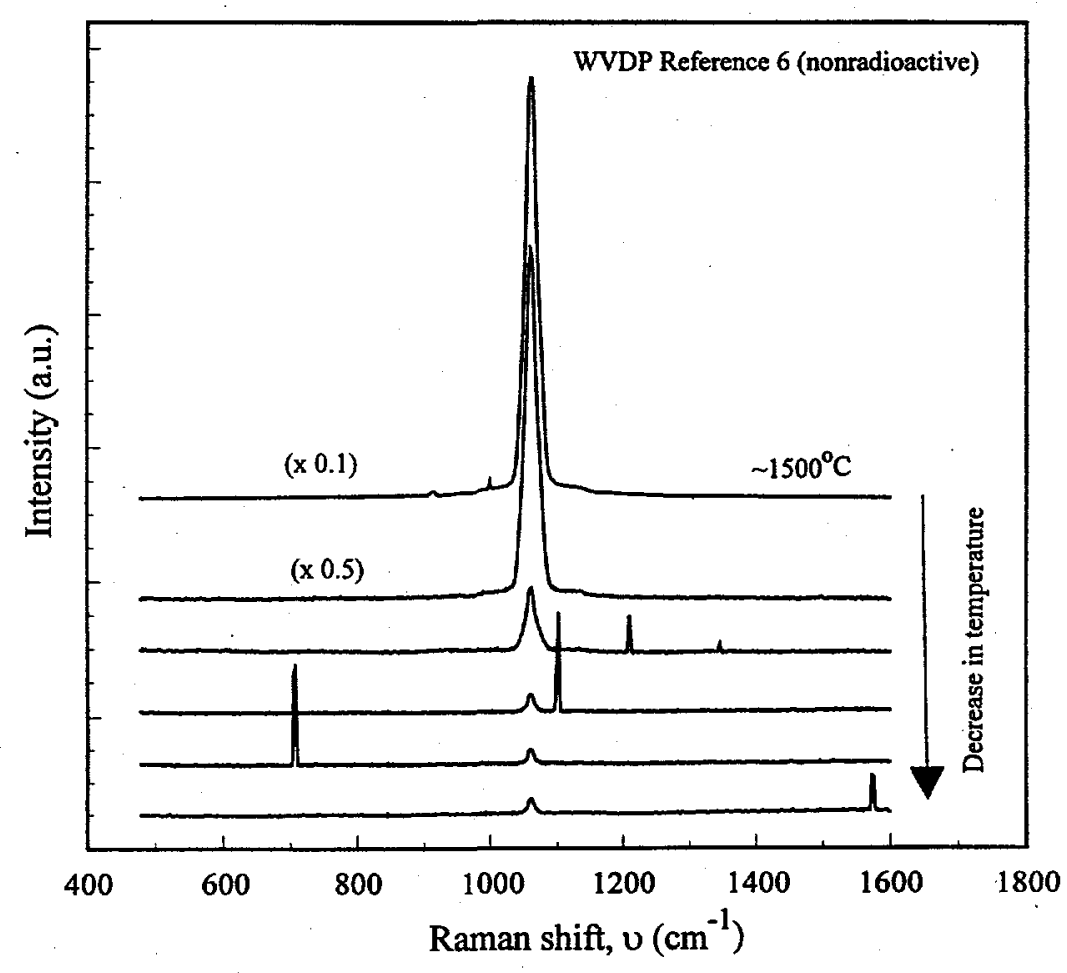

Figure 4.6. High-temperature Raman Spectra of the REF 6 Glass Collected Using the Renishaw UV Confocal Raman Microspectrometer with a Laser Excitation Line of $325 \mathrm{~nm}$ 
Raman spectroscopy. Further testing is required to evaluate the potential use of the UV Raman for HLW glass database development. Based on the quality of the data collected for the high-iron borosilicate waste glass, REF 6, the UV confocal Raman microspectrometer is expected to be able to perform hightemperature Raman measurements for other HLW glasses.

In summary, a continuous wave method with a $325-\mathrm{nm}$ laser can be used to perform hightemperature Raman measurements for both transparent silicate glasses and deep-colored HLW glasses. No black-body radiation effect on Raman scattering was evident for either glass system when a UV confocal Raman miscrospectrometer was used to collect the data. The major advantage of using a UV confocal Raman microspectrometer over the pulse-gating Raman setup ${ }^{(a)}$ is its operation efficiency; the glass melt can be easily focused for measurement at each given temperature. Therefore, for developing Raman databases for molten glasses, the use of UV confocal Raman microspectrometer would provide significant research time and cost savings. However, for practical application in melter control, other optical techniques shall be evaluated on the basis of operation efficiency, data quality, and equipment cost. That evaluation is beyond the scope of this Phase I study, and is planned for Phase III should funding for this work continue.

(a) The pulse-gating Raman setup inherently has difficulty in optimizing the setup and focusing the melt at each temperature compared with a Raman spectrometer with microscope attachment such as the UVconfocal Raman microspectrometer. 


\subsection{Statistical Modeling - Raman Data, Temperature, and Composition}

Several papers (Mysen and Frantz 1994a, 1994b; Mysen 1995; Neuville and Mysen 1996) contain Raman spectroscopy data for binary or psuedo-binary glass compositions over a range of melt temperatures. Data plots in these papers show strong relationships between Raman parameters, glass composition, and melt temperature. These strong relationships suggest it is feasible to estimate glass composition and melt temperature based on high-temperature Raman data. However, these papers have not investigated using statistical multivariate calibration methods (see Appendix A) for estimating glass composition and melt temperature from high-temperature Raman data.

In the following subsections, data plots and statistical calibration methods are used to develop relationships for estimating glass composition and melt temperature from high-temperature Raman data. The data developed as part of this project (see Sections 3 and 4) are addressed in Section 5.1, while the data from Mysen and Frantz (1994b) are addressed in Section 5.2. Both of these data sets involve only binary or pseudo-binary variations in glass composition, but are appropriate for an initial feasibility study such as this one.

\subsection{PNNL Sodium-Silicate Glass Data}

The Raman data for the sodium-silicate glasses listed in Table 4.1 are plotted versus temperature and $\mathrm{Na}_{2} \mathrm{O}$ content (mol\%) in Appendix B. The plots in Figures B.1 to B.3 show varying degrees of linear relationships between Raman parameters (peak frequencies, peak FWHMs, and peak proportional areas) and temperature. The plots in Figures B.4 to B.6 show varying degrees of curvilinear relationships between the Raman parameters and $\mathrm{Na}_{2} \mathrm{O}$ content.

The relationships in Figures B.1 to B.6 are rather "noisy" because of the data collection problems discussed in Section 4.0. The limited usable data for the OMMS-9803 glass (results for only three temperatures) makes it difficult to assess a temperature relationship for that glass and to assess the effects of varying $\mathrm{Na}_{2} \mathrm{O}$ content in sodium-silicate glasses. Because of these difficulties and limitations of the data, it was decided not to pursue developing statistical multivariate calibration equations for these data but instead to pursue this aspect of the feasibility study using a literature data set, as described in Section 5.2.

\subsection{Mysen and Frantz Sodium-Alumino-Silicate Glass Data}

Mysen and Frantz (1994b) published Raman data over a range of temperatures for five pseudobinary mixtures of $\mathrm{Na}_{2} \mathrm{Si}_{2} \mathrm{O}_{5}$ (or $\mathrm{Na}_{2} \mathrm{O} \cdot 2 \mathrm{SiO}_{2}=\mathrm{NS} 2$ ) and $\mathrm{Na}_{2}(\mathrm{NaAl})_{2} \mathrm{O}_{5}$ (or $2 \mathrm{Na}_{2} \mathrm{O} \cdot \mathrm{Al}_{2} \mathrm{O}_{3}=2 \mathrm{NA}$ ). The notation and various representations for the five compositions are listed in Table 5.1. Although the glass compositions may be expressed involving the oxides $\mathrm{Na}_{2} \mathrm{O}, \mathrm{SiO}_{2}$, and $\mathrm{Al}_{2} \mathrm{O}_{3}$, essentially only a onedimensional variation in composition occurs. Table 5.1 provides several choices of variables to express 
Table 5.1. Notation and Various Representations of Composition for Five Glasses Studied by Mysen and Frantz (1994b)

\begin{tabular}{|c|c|c|c|c|c|c|c|}
\hline Glass $^{(2)}$ & $\begin{array}{c}\mathrm{Na}_{2} \mathrm{Si}_{2} \mathrm{O}_{5} \\
(\mathrm{~mol} \%)\end{array}$ & $\begin{array}{c}\mathrm{Na}_{2}(\mathrm{NaAl})_{2} \mathrm{O}_{5} \\
(\mathrm{~mol} \%)\end{array}$ & $\begin{array}{c}\mathrm{Na}_{2} \mathrm{O} \\
(\mathrm{mol} \%)\end{array}$ & $\begin{array}{c}\mathrm{SiO}_{2} \\
(\mathrm{~mol} \%)\end{array}$ & $\begin{array}{c}\mathrm{Al}_{2} \mathrm{O}_{3} \\
(\mathrm{~mol} \%)\end{array}$ & $\mathbf{A l} / \mathbf{S i}$ & $\mathbf{A l} /(\mathbf{A l}+\mathbf{S i})$ \\
\hline (NS2) 100 & 100 & 0 & 33.33 & 66.67 & 0.00 & 0.00 & 0.00 \\
\hline$(\mathrm{NS} 2) 95$ & 95 & 5 & 35.00 & 63.33 & 1.67 & 0.03 & 0.03 \\
\hline (NS2)90 & 90 & 10 & 36.67 & 60.00 & 3.33 & 0.06 & 0.06 \\
\hline (NS2)80 & 80 & 20 & 40.00 & 53.33 & 6.67 & 0.14 & 0.12 \\
\hline$(\mathrm{NS} 2) 70$ & 70 & 30 & 43.33 & 46.67 & 10.00 & 0.24 & 0.20 \\
\hline
\end{tabular}

the one-dimensional variation of composition. These variables are highly (in some cases perfectly) correlated, and there appears to be no strong reason to select one versus another to represent the composition variation. In this report, the mole percent (mol\%) of $\mathrm{Al}_{2} \mathrm{O}_{3}$ is used to represent the change in glass composition.

The Raman parameters published by Mysen and Frantz (1994b) include the frequency, FWHM, and integrated area of fitted Gaussian peaks at nominal frequencies of $900,950,1050$, and $1100 \mathrm{~cm}^{-1}$. Raman measurements were made at test temperatures ranging from 25 to over $1300^{\circ} \mathrm{C}$ depending on the glass composition. Only the data above $700^{\circ} \mathrm{C}$ were used for our investigation, because our interest is in: 1) glass melts at higher temperatures, and 2) efficient development of calibration equations using only higher-temperature Raman data.

Rather than using integrated peak areas $\left(\mathrm{A}_{i}\right)$ to develop calibration equations, proportional peak areas,

$$
a_{i}=A_{i} /\left(A_{900}+A_{950}+A_{1050}+A_{1100}\right) \text { for } I=900,950,1050 \text {, and } 1100
$$

were used. This "normalization" of peak areas removes differences that may occur over time in Raman measurements. Other normalizations are possible. For example, Mysen and Frantz (1994b) used $A_{i} /\left(A_{900}+A_{950}+A_{1100}\right)$ for $I=900,950$, and 1100 , apparently due to uncertainty and controversy about the structural meaning of the $1050 \mathrm{~cm}^{-1}$ peak. However, from the statistical perspective, there is no reason to discard the area data for the $1050 \mathrm{~cm}^{-1}$ peak, since data plots in Appendix $C$ suggest that the $1050 \mathrm{~cm}^{-1}$ peak data might be useful in developing calibration equations.

The Mysen and Frantz (1994b) data used in this study are listed in Table 5.2. The frequencies and FWHMs of the fitted Gaussian peaks are those published by Mysen and Frantz (1994b). The proportional areas were computed from the integrated areas published by Mysen and Frantz (1994b). The 
Table 5.2 Raman Data for Five Glasses Studied by Mysen and Frantz (1994b)

\begin{tabular}{|c|c|c|c|c|c|c|c|c|c|c|c|c|c|}
\hline \multirow[b]{2}{*}{ Glass } & \multirow[b]{2}{*}{$\begin{array}{c}\text { Temp. } \\
\left({ }^{\circ} \mathrm{C}\right)\end{array}$} & \multicolumn{4}{|c|}{$\overline{\mathrm{ncy}, \mathrm{cm}^{-1(2)}}$} & \multicolumn{4}{|c|}{ Peak FWHM, cm $^{-1(b)}$} & \multicolumn{4}{|c|}{$\overline{\text { Peak Proportional Area }}^{(\mathrm{c})}$} \\
\hline & & 900 & 950 & 150 & 00 & 900 & 950 & 150 & 100 & 900 & 50 & 1050 & 1100 \\
\hline 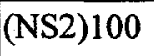 & 8 & 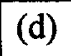 & 9 & 5 & 4 & 0 & 38 & 76 & 35 & 0 & 1 & 9 & 0.361551 \\
\hline & 773 & ) & 934 & 1074 & -1 & 0 & 39 & 77 & 35 & & & 76215 & . \\
\hline S2) 100 & 5 & 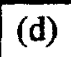 & 934 & 074 & 1093 & 0 & 39 & 76 & 35 & 10 & & 516 & 0.354351 \\
\hline & 878 & ) & 932 & 1071 & 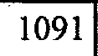 & 0 & 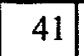 & 77 & 36 & 10 & & 8729 & 4727 \\
\hline 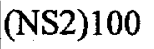 & 929 & ) & 931 & 1070 & 1090 & 0 & 74 & 78 & 36 & 0.000000 & 0.065742 & 0.608028 & 0.326231 \\
\hline 0 & 996 & ) & 930 & 1071 & 1090 & 0 & 42 & .79 & 37 & 0.000000 & 85 & 6980 & .318535 \\
\hline IS2) 100 & 52 & & 929 & 70 & 1090 & 0 & 43 & 79 & 37 & 10 & & 178 & 8 \\
\hline S?) & 714 & 1 & 931 & 1052 & 1084 & 30 & 35 & 80 & 36 & 956 & & 4723 & 0.322509 \\
\hline 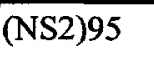 & 765 & & 930 & 1051 & 1083 & 31 & 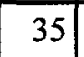 & 82 & 36 & 0.012837 & & 333 & 100 \\
\hline S2)95 & 813 & 0 & 929 & 1049 & 1082 & 31 & 35 & 82 & 37 & 0.013533 & 220 & 2986 & 0.310262 \\
\hline (NS2)95 & 864 & 8 & 928 & 1048 & 081 & 34 & 20 & 83 & 37 & & & 53 & 84 \\
\hline IS2)95 & 19 & 865 & 927 & 1047 & 1080 & 34 & 37 & 83 & 38 & 0.015478 & & 9125 & 0.286137 \\
\hline ניק & 0 & 5 & 926 & 046 & 79 & 0 & 37 & 84 & 38 & 6 & & 260 & 0.277588 \\
\hline JS2) 95 & 09 & 55 & 925 & 1044 & 078 & 40 & 38 & 85 & 38 & 0.020558 & 199 & 6983 & 0.272260 \\
\hline (NS3)05 & 0 & 1 & 923 & 1042 & 1077 & 39 & 38 & 8 & 39 & 64 & & 987 & . \\
\hline S2)95 & 09 & 0 & 923 & 1042 & 1076 & 43 & 39 & 86 & 39 & 137 & 83 & 8884 & 3896 \\
\hline 6) & 0 & 7 & 922 & 1043 & 1076 & 45 & 40 & 87 & 39 & 15 & & 843 & 1134 \\
\hline IS2)95 & 41 & 4 & 920 & 1041 & 075 & 3 & 42 & 87 & 39 & 2543 & 86 & 988 & 283 \\
\hline 99 & 19 & 7 & 919 & 341 & 74 & 40 & $A$ & 85 & 39 & 32 & 22 & 927 & 2319 \\
\hline (IV) & 2 & 7 & 929 & 1 & 1080 & 34 & 36 & 8 & 38 & 34 & & 272 & 0.292024 \\
\hline JS & 803 & 865 & 927 & 1038 & 79 & 36 & 36 & 87 & 39 & 279 & 36 & 4599 & 0.291085 \\
\hline (NS2)90 & 856 & 5 & 927 & 37 & 1077 & 38 & 36 & 88 & 40 & 4 & & 77 & 0.285355 \\
\hline (NS2)90 & 07 & 861 & 925 & 1038 & 1077 & 36 & 38 & 87 & 39 & 0.1 & 22 & 596 & 2613 \\
\hline (NS2) 90 & $=9$ & 9 & 924 & 1037 & 76 & 37 & 38 & 8 & 40 & 77 & 15 & 4460 & 0.260748 \\
\hline (NS2)90 & 01 & 859 & 923 & 1035 & 1075 & 37 & 8 & 80 & 40 & 0.019474 & 93 & 412 & 521 \\
\hline 100 & 44 & 7 & 923 & 1036 & 74 & 39 & 39 & 8 & 40 & 78 & 39 & 0.597099 & 0.240184 \\
\hline$(1032)$ & 94 & 856 & 921 & 1034 & 1073 & 38 & 40 & 90 & 40 & 0.021316 & 0.14 & 6389 & 0.242050 \\
\hline IaIC?) & 1146 & 854 & 921 & 35 & 73 & 11 & 1 & 89 & 40 & 8 & 1 & 99 & tit \\
\hline (NS2) 90 & 207 & 853 & 919 & 1032 & 1072 & 41 & 41 & 91 & 41 & 0.024736 & 0.140994 & 0.611086 & 0.223184 \\
\hline NS2)80 & 739 & 2 & 925 & 0 & 1066 & 34 & 40 & 86 & 39 & 81 & 05 & 117 & 0.153698 \\
\hline
\end{tabular}


Table 5.2. (contd)

\begin{tabular}{|c|c|c|c|c|c|c|c|c|c|c|c|c|c|}
\hline \multirow[b]{2}{*}{ Glass } & \multirow[b]{2}{*}{$\begin{array}{c}\text { Temp. } \\
\left({ }^{\circ} \mathrm{C}\right)\end{array}$} & \multicolumn{4}{|c|}{ Peak Frequency, cm $^{-1(a)}$} & \multicolumn{4}{|c|}{ Peak FWHM, cm $^{-1(b)}$} & \multicolumn{4}{|c|}{ Peak Proportional Area ${ }^{(c)}$} \\
\hline & & 900 & 950 & 1050 & 1100 & 900 & 950 & 1050 & 1100 & 900 & 950 & 1050 & 1100 \\
\hline$(\mathrm{NS} 2) 80$ & 793 & 850 & 924 & 1010 & 1065 & 35 & 41 & 85 & 39 & 0.027783 & 0.163058 & 0.665070 & 0.144089 \\
\hline$(\mathrm{NS} 2) 80$ & 863 & 847 & 922 & 1009 & 1064 & 36 & 42 & 87 & 39 & 0.030079 & 0.160766 & 0.671462 & 0.137693 \\
\hline (NS2)80 & 914 & 846 & 921 & 1008 & 1063 & 37 & 42 & 87 & 39 & 0.031430 & 0.164311 & 0.668960 & 0.135298 \\
\hline (NS2)80 & 954 & 846 & 921 & 1008 & 1062 & 38 & 42 & 88 & 39 & 0.033524 & 0.160987 & 0.676736 & 0.128753 \\
\hline$($ NS2) 80 & 1006 & 844 & 919 & 1006 & 1061 & 39 & 42 & 90 & 40 & 0.033242 & 0.153571 & 0.683242 & 0.129945 \\
\hline$(\mathrm{NS} 2) 70$ & 755 & 840 & 917 & 989 & 1058 & 32 & 44 & 89 & 35 & 0.024665 & 0.147014 & 0.747139 & 0.081182 \\
\hline$(\mathrm{NS} 2) 70$ & 809 & 839 & 916 & 995 & 1058 & 34 & 47 & 86 & 34 & 0.030033 & 0.196407 & 0.704333 & 0.069227 \\
\hline (NS2)70 & 859 & 837 & 914 & 991 & 1056 & 34 & 46 & 89 & 35 & 0.029491 & 0.167786 & 0.727860 & 0.074863 \\
\hline (NS2)70 & 918 & 836 & 914 & 993 & 1056 & 36 & 47 & 88 & 35 & 0.034512 & 0.185365 & 0.710838 & 0.069285 \\
\hline$(\mathrm{NS} 2) 70^{(\mathrm{e})}$ & 971 & 835 & 915 & 1001 & 1055 & 38 & 51 & 83 & 33 & 0.040238 & 0.254954 & 0.652938 & 0.051870 \\
\hline (NS2)70 & 1022 & 833 & 912 & 993 & 1053 & 37 & 49 & 88 & 36 & 0.038494 & 0.201198 & 0.696407 & 0.063901 \\
\hline$(\mathrm{NS} 2) 70$ & 1082 & 833 & 910 & 989 & 1052 & 38 & 47 & 91 & 37 & 0.039044 & 0.169871 & 0.721589 & 0.069496 \\
\hline \multicolumn{14}{|c|}{$\begin{array}{l}\text { (a) Frequency (location) of fitted Gaussian peak with nominal frequency } 900,950,1050, \text { or } 1100 \mathrm{~cm}^{-1} . \\
\text { (b) Full width at half maximum of fitted Gaussian peak with nominal frequency } 900,950,1050 \text {, or } 1100 \mathrm{~cm}^{-1} \text {. } \\
\text { (c) Proportional area of fitted Gaussian peak with nominal frequency } 900,950,1050 \text {, or } 1100 \mathrm{~cm}^{-1} \text {. For example, } \\
a_{900}=A_{900}\left(A_{900}+A_{950}+A_{1050}+A_{1100}\right) \text {, where } A_{\mathrm{i}} \text { is the integrated area of the I-th peak from Mysen and Frantz } \\
(1994 \mathrm{~b}) \text {. } \\
\text { (d) A peak at nominal frequency of } 900 \mathrm{~cm}^{-1} \text { was not fitted for this glass. } \\
\text { (e) The peak FWHMs W950, W1050, and W1100 and the peak proportional areas } a_{950}, a_{1050} \text {, and } a_{1100} \text { listed in } \\
\text { boldface are outliers, and were not used in developing calibration equations in this report. }\end{array}$} \\
\hline
\end{tabular}

values of $\mathrm{FWHM}_{\mathrm{i}}$ and $\mathrm{a}_{\mathrm{i}}$ for the $900 \mathrm{~cm}^{-1}$ peak of the (NS2)100 melt were given zero values for all temperatures, because the $900 \mathrm{~cm}^{-1}$ peaks were not fitted for that composition at any of the test temperatures. In what follows, we use the notation: 1) $\mathrm{F}_{900}, \mathrm{~F}_{950}, \mathrm{~F}_{1050}$, and $\mathrm{F}_{1100}$ to denote the frequencies of the fitted peaks, 2) $\mathrm{W}_{900}, \mathrm{~W}_{950}, \mathrm{~W}_{1050}$, and $\mathrm{W}_{1100}$ to denote FWHMs of the fitted peaks, and 3) $\mathrm{a}_{900}, \mathrm{a}_{950}, \mathrm{a}_{1050}$, and $a_{1100}$ to denote proportional areas of the fitted peaks. Henceforth, we refer to the $F_{i}, W_{i}$, and $a_{i}$ as the Raman parameters.

Appendix $\mathrm{C}$ contains scatter plots of the Raman parameters versus melt temperature $\left({ }^{\circ} \mathrm{C}\right)$ and glass composition in terms of $\mathrm{Al}_{2} \mathrm{O}_{3}(\mathrm{~mol} \%)$. Figures $\mathrm{C} .1$ to $\mathrm{C} .3$ show that the Raman parameters are generally linear functions of temperature, although the linear relationships are stronger for some parameters and weaker for others. Figures C. 4 to C. 6 show that the Raman parameters are approximately linear or quadratic functions of $\mathrm{Al}_{2} \mathrm{O}_{3}$ concentrations in the glasses. In some cases it appears other nonlinear relationships besides quadratic may be appropriate. However, without additional knowledge or assumptions 
regarding Raman parameters for glasses with higher levels of $\mathrm{Al}_{2} \mathrm{O}_{3}$, it is difficult to know the proper nonlinear relationship between Raman parameters and $\mathrm{Al}_{2} \mathrm{O}_{3}$. In this report, we assume a linear or quadratic relationship between Raman parameters and the concentration of $\mathrm{Al}_{2} \mathrm{O}_{3}$ is adequate for calibration purposes.

\subsubsection{Classical Calibration Approach}

The plots in Appendix $\mathrm{C}$ suggest that the calibration equation

$$
\begin{aligned}
y & =\left(c_{0}+c_{1} x+c_{2} x^{2}+c_{3} x^{3}\right)+\left(d_{0}+d_{1} x+d_{2} x^{2}\right) T \\
& =c_{0}+c_{1} x+c_{2} x^{2}+c_{3} x^{3}+d_{0} T+d_{1} x T+d_{2} x^{2} T,
\end{aligned}
$$

or reduced forms thereof, will adequately approximate the unknown relationships between Raman parameters $(y)$, glass composition (represented by $\mathrm{x}=\mathrm{Al}_{2} \mathrm{O}_{3}$ mol\%), and melt temperature $(\mathrm{T})$. In Eq. (5.2), the $c_{i}$ and $d_{i}$ are coefficients to be fitted using a regression method applied to a calibration data set. Note that this form of equation is based on the classical calibration approach outlined in Appen$\operatorname{dix}$ A. The classical calibration approach is appropriate because in the Mysen and Frantz data (1994b), the regressor variables, $\mathrm{x}$ and $\mathrm{T}$, are known with little uncertainty compared to the larger uncertainties in the $y$ variables.

For reasons to be explained shortly, the values of the Raman parameters were standardized prior to fitting calibration equations of the form in Eq. (5.2). Standardizing refers to subtracting the mean and dividing by the standard deviation so that the standardized values of each Raman parameter have mean zero and standard deviation of 1 . Standardizing the values of a response variable (Raman parameter) changes the coefficients of a calibration equation but does not change the fit of the calibration equation. However, predictions from a "standardized" calibration equation can be easily converted to predictions that would have been obtained without standardizing by multiplying each standardized prediction by the standard deviation and adding the mean for the corresponding Raman parameter.

Table 5.3 summarizes the results of fitting Eq. (5.2) to the standardized Raman parameters, melt temperature, and glass composition data in Tables 5.1 and 5.2. For all Raman parameters, it was possible to fit reduced forms of Eq. (5.2), as seen in Table 5.3. The $\mathrm{R}^{2}$ and s values given in Table 5.3 (see table footnotes for definitions) provide for assessing the goodness-of-fit of the fitted equations. These statistics show that Eq. (5.2), or reduced forms thereof, fit the data very well for most Raman parameters. The best fits were obtained for the peak proportional areas $\left(0.973 \leq R^{2} \leq 0.978\right)$ and the peak frequencies $\left(0.984 \leq R^{2} \leq 0.991\right)$. The fits for peak widths were not as good $\left(0.733 \leq R^{2} \leq 0.924\right)$, but good enough to potentially still be useful for multivariate calibration.

Scatter plots of the Raman parameters versus one another (not included in the report) show that they are highly correlated. Hence, the "independent information" contained in the parameters $F_{900}, F_{950}, F_{1050}$, $F_{1100}, W_{900}, W_{950}, W_{1050}, W_{1100}, a_{900}, a_{950}, a_{1050}$, and $a_{1100}$ is far less than the number of parameters would seem to indicate. Several multivariate calibration modeling methods (e.g., principal components 
Table 5.3. Results of Fitting Classical Calibration Equations to Mysen and Frantz (1994b) Data

\begin{tabular}{|c|c|c|c|c|c|c|c|c|c|c|c|c|}
\hline \multirow[b]{2}{*}{ Term } & \multicolumn{12}{|c|}{ Standardized $^{(a)}$ Versions of Raman Parameters } \\
\hline & $F_{900}{ }^{(b)}$ & $F_{950}$ & $F_{1050}$ & $F_{1100}$ & $W_{900^{(b)}}$ & $W_{950}^{(c)}$ & $W_{1050^{(c)}}$ & $W_{1100}{ }^{(c)}$ & $a_{900}$ & $a_{950}{ }^{(c)}$ & $a_{1050}^{(c)}$ & $\mathbf{a}_{1100}$ \\
\hline Int. ${ }^{(d)}$ & 3.890932 & 4.252705 & 2.329820 & 2.721518 & -5.318220 & -2.978281 & -4.022965 & -3.551747 & -1.740320 & (f) & -2.478487 & 2.990515 \\
\hline $\mathrm{x}$ & 0.075380 & -0.512614 & -0.569561 & -0.419383 & (e) & -0.350243 & 0.732837 & 0.848343 & (e) & (f) & -0.503778 & -0.452340 \\
\hline$x^{2}$ & -0.106285 & 0.076321 & 0.016096 & 0.012915 & (e) & 0.056265 & -0.051403 & -0.085985 & (e) & (f) & 0.244452 & (e) \\
\hline$x^{3}$ & 0.006260 & -0.005319 & (e) & (e) & (e) & (e) & (e) & (e) & (e) & (f) & -0.014769 & (e) \\
\hline $\mathrm{T}$ & -0.003192 & -0.003305 & -0.001064 & -0.001521 & 0.005575 & 0.003082 & 0.002709 & 0.002656 & (e) & (f) & 0.002432 & -0.001995 \\
\hline XT & 0.000122 & (e) & 0.000128 & (e) & (e) & (e) & (e) & (e) & 0.000773 & (f) & -0.000289 & 0.000179 \\
\hline$x^{2} T$ & (e) & (e) & (e) & (e) & (e) & (e) & (e) & (e) & -0.000046 & (f) & (e) & (e) \\
\hline $\mathbf{R}^{2(\mathrm{~g})}$ & 0.984 & 0.991 & 0.986 & 0.984 & 0.733 & 0.873 & 0.892 & 0.924 & 0.975 & (f) & 0.973 & 0.978 \\
\hline$s^{(h)}$ & 0.1357 & 0.1011 & 0.1264 & 0.1300 & 0.5246 & 0.3704 & 0.3412 & 0.2875 & 0.3252 & (f) & 0.1751 & 0.1535 \\
\hline \multicolumn{13}{|c|}{$\begin{array}{l}\text { (a) Standardizing refers to subtracting the mean and dividing by the standard deviation. See text for additional explanation. } \\
\text { (b) Not applicable to (NS2)100 glass. In the case of } \mathrm{w}_{900} \text {, a more complicated equation could be derived that would be applicable to (NS2)100. } \\
\text { (c) Data point for glass (NS2)70 at } 971^{\circ} \mathrm{C} \text { was deleted as an outlier, and not used in developing the equation. } \\
\text { (d) Intercept, i.e., the constant term } \mathrm{c}_{0} \text { in the calibration equation in Eq. (5.2). } \\
\text { (e) Blank table entries indicate those terms are not included in the calibration equation (i.e., those terms have zero coefficients). } \\
\text { (f) Various models were fitted, but none was good enough to use for calibration purposes. This is likely because of the weak, noisy relationships a } a_{950} \text { has } \\
\text { with temperature for the glasses studied (see Figure C.3), and the strange relationships with } x \text { (see Figure C.6). } \\
\text { (g) } \mathrm{R}^{2} \text { is the fraction of variation in a response variable (e.g., a Raman parameter in this application) accounted for by the fitted equation. Hence, } \mathrm{R}^{2} \\
\text { must be between } 0 \text { and } 1 \text {, with values closer to } 1 \text { indicating better fits. } \\
\text { (h) "s" is an estimate of the experimental error standard deviation if the fitted equation adequately approximates the true relationship. The units of "s" are } \\
\text { the same as the response variable (e.g., the Raman parameter in this application). }\end{array}$} \\
\hline
\end{tabular}


regression and partial least squares regression) account for high correlations among variables, but such methods are not used in the classical calibration approach presented here.

The fitted calibration equations reported in Table 5.3 can be used to estimate temperature (T) and $\mathrm{Al}_{2} \mathrm{O}_{3}(\mathrm{x})$ as functions of the Raman parameters $\mathrm{F}_{900}, \mathrm{~F}_{950}, \mathrm{~F}_{1050}, \mathrm{~F}_{11009}, \mathrm{~W}_{900}, \mathrm{~W}_{950}, \mathrm{~W}_{1050}, \mathrm{~W}_{1100}, \mathrm{a}_{900}, \mathrm{a}_{950}$, $a_{1050}$, and $a_{1100}$ for cases where Raman data have been collected but composition and melt temperature are unknown. This is done by "inverting" the classical calibration equations, as introduced in Appendix A. Specifically, the equations are "inverted" by simultaneously solving them for each case where $T$ and $x$ are to be estimated given measured Raman data.

To clarify the concept of inverting classical calibration equations for our application to the Mysen and Frantz (1994b) data, consider:

$$
\begin{gathered}
y_{1}^{\prime}=f_{1}(x, T) \\
y_{2}^{\prime}=f c t_{2}(x, T) \\
\cdot \\
\cdot \\
y_{9}^{\prime}=f^{\cdot}
\end{gathered}
$$

where $y_{1}^{\prime}, y_{2}^{\prime}, \ldots, y_{9}^{\prime}$ represent standardized versions of $F_{950}, F_{1050}, F_{1100}, W_{950}, W_{1050}, W_{1100}, a_{900}, a_{1050}$, and $\mathrm{a}_{1100}$, and $\mathrm{fct}_{1}(\mathrm{x}, \mathrm{T}), \mathrm{fct}_{2}(\mathrm{x}, \mathrm{T}) \ldots, \mathrm{fct}_{9}(\mathrm{x}, \mathrm{T})$ represent the corresponding standardized calibration equations of the form (5) whose coefficients are given in Table 5.3. Note that $F_{900}$ and $W_{900}$ are not included, because peaks at nominal frequencies of $900 \mathrm{~cm}^{-1}$ were not fitted for the (NS2) 100 glass. Further, $a_{950}$ is not included because: (I) the mixture constraint that the $a_{i}$ sum to one causes a perfect collinearity, and (ii) $\mathrm{a}_{950}$ correlated with $\mathrm{x}$ and $\mathrm{T}$ so poorly that a calibration equation was not developed. Now, for cases where the Raman measurements have been made and $x$ and $T$ are to be estimated, Eq. (5.3) represents a system of nine equations in two unknowns ( $x$ and $T$ ).

The system of equations (5.3) must be solved by nonlinear least squares because the $\mathrm{fct}_{i}(\mathrm{x}, \mathrm{T})$ are nonlinear functions of $\mathrm{x}$ and $\mathrm{T}$, as seen from Eq. (5.2). Further, nonlinear weighted least squares is needed, because the nine equations do not all fit equally well. Weights given by WEIGHT $=1 / \mathrm{s}^{2}$ (where $\mathrm{s}$ values are given for each equation in Table 5.3) were used. Finally, in order to apply nonlinear least squares, there must be a common response variable. The purpose of standardizing the Raman parameters before fitting the calibration equations in Table 5.3 was so that the standardized Raman parameters could be treated as a common variable for this "inversion" stage of the multivariate classical calibration approach. That is, standardizing the Raman parameters before fitting the calibration equations makes it appropriate to minimize the sum of squared errors (in standardized Raman parameters) across the collection of calibration equations.

The performance of the nine calibration equations described above was assessed by applying the equations to the data in Tables 5.1 and 5.2. That is, the nine equations were simultaneously solved via nonlinear weighted least squares for each data point in Table 5.2. In this case, the data used to develop 
the calibration equations are also being used to assess performance of the equations. Ideally, a separate set of validation data not used in developing the calibration equations should be used to assess performance, but no such data are available. Cross-validation methods ${ }^{(2)}$ could be used with the existing data to more validly assess performance, but doing so was beyond the scope of this initial feasibility effort.

The results of applying the nine calibration equations to the data used to develop them are given in Table 5.4. The $\mathrm{R}^{2}$ values (proportion of variation in the data accounted for by the calibration equations) are $\mathrm{R}^{2}=0.990$ for $\mathrm{x}=\mathrm{Al}_{2} \mathrm{O}_{3}(\mathrm{~mol} \%)$ and $\mathrm{R}^{2}=0.951$ for $\mathrm{T}\left({ }^{\circ} \mathrm{C}\right)$. These values are very good, indicating that the calibration equations account for the vast majority of the variation in the actual $\mathrm{x}$ and $\mathrm{T}$ values. The predicted and actual values of $\mathrm{x}$ and $\mathrm{T}$ summarized in Table 5.4 are displayed graphically in Figures 5.1 and 5.2. Again, these figures show that the classical calibration approach performs very well. However, it is clear the equations are over-predicting the $\mathrm{Al}_{2} \mathrm{O}_{3}$ mol\% content of the (NS2)95 glass, and under-predicting the $\mathrm{Al}_{2} \mathrm{O}_{3}$ mol\% content of the (NS2) 90 glass. The plots of the Raman parameters versus $\mathrm{Al}_{2} \mathrm{O}_{3}$ content in Appendix C Figures C. 4 to C.6 showed somewhat odd behavior for these two glasses, so it is understandable that the multivariate calibration equation predictions may be biased (or appear to be biased) for those glasses.

\subsubsection{Inverse Calibration Approach}

The inverse calibration approach described in Appendix A was also applied to the Mysen and Frantz data (1994b). With this approach, the glass melt temperature $(\mathrm{T})$ and composition (as represented by $\mathrm{x}=$ $\mathrm{Al}_{2} \mathrm{O}_{3} \mathrm{~mol} \%$ ) are modeled as functions of the Raman parameters. Specifically, calibration equations were developed using subsets of the Raman parameters, as described below.

Least squares "all-subsets" multiple regression was used to develop inverse calibration equations of the form

$$
\begin{aligned}
& x=\alpha_{0}+\alpha_{1} R_{1}+\alpha_{2} R_{2}+\ldots+\alpha_{h} R_{h}, \\
& T=\beta_{0}+\beta_{1} R_{1}+\beta_{2} R_{2}+\ldots+\beta_{k} R_{k},
\end{aligned}
$$

where $R_{1}, \ldots, R_{h}$ and $R_{1}, \ldots, R_{k}$ represent potentially different subsets of the Raman parameters $F_{950}, F_{1050}$, $\mathrm{F}_{1100}, \mathrm{~W}_{950}, \mathrm{~W}_{1050}, \mathrm{~W}_{1100}, \mathrm{a}_{900}, \mathrm{a}_{1050}$, and $\mathrm{a}_{1100}$. In "all-subsets" regression, equations including all possible subsets of one, two, ..., up to the total number of possible predictor variables are fitted via least squares. Then, the best few equations of each size are compared to determine when the addition of more variables to the equation fails to improve the fit. The smallest best-fitting equation is then selected. In this application, the predictor variables are the nine Raman parameters $F_{950}, F_{1050}, F_{1100}, W_{950}, W_{1050}, W_{1100}, a_{900}$,

(a) Cross-validation methods successively omit subsets of the data, consisting of one or more data points, and repeat the estimation process for each successive iteration. The calibration equations for each iteration differ slightly, but the predictions for the "left out" data provide for properly validating the performance of the calibration equations for data not used to develop the equations. 
Table 5.4 Classical and Inverse Calibration Results for Mysen and Frantz Data (1994b)

\begin{tabular}{|c|c|c|c|c|c|c|}
\hline \multirow{3}{*}{ Glass } & \multicolumn{3}{|c|}{ Temperature $\left({ }^{\circ} \mathrm{C}\right)$} & \multicolumn{3}{|c|}{$\mathrm{Al}_{2} \mathrm{O}_{3}(\mathrm{~mol} \%)$} \\
\hline & \multirow[b]{2}{*}{ Actual } & \multicolumn{2}{|c|}{ Calibration Predicted } & \multirow[b]{2}{*}{ Actual } & \multicolumn{2}{|c|}{ Calibration Predicted } \\
\hline & & Classical( $^{(a)}$ & Inverse $^{(\mathbf{b})}$ & & Classical $^{(x)}$ & Inverse $^{(b)}$ \\
\hline$(\mathrm{NS} 2) 100$ & 718 & 735 & 759 & 0.00 & $0.00^{(\mathrm{c})}$ & $0.00^{(\mathrm{d})}$ \\
\hline (NS2) 100 & 773 & 784 & 787 & 0.00 & $0.00^{(\mathrm{c})}$ & $0.00^{(\mathrm{d})}$ \\
\hline (NS2) 100 & 825 & 782 & 788 & 0.00 & $0.00^{(\mathrm{c})}$ & $0.00^{(d)}$ \\
\hline (NS2) 100 & 878 & 895 & 878 & 0.00 & $0.00^{(\mathrm{c})}$ & 0.17 \\
\hline (NS2) 100 & 929 & 945 & 911 & 0.00 & $0.00^{(\mathrm{c})}$ & 0.47 \\
\hline (NS2) 100 & 996 & 994 & 1024 & 0.00 & $0.00^{(\mathrm{c})}$ & $0.00^{(d)}$ \\
\hline (NS2) 100 & 1052 & 1030 & 1037 & 0.00 & $0.00^{(\mathrm{c})}$ & 0.07 \\
\hline (NS2)95 & 714 & 686 & 711 & 1.67 & 1.93 & 1.65 \\
\hline (NS2)95 & 765 & 725 & 748 & 1.67 & 2.00 & 1.78 \\
\hline (NS2)95 & 813 & 763 & 808 & 1.67 & 2.14 & 1.54 \\
\hline (NS2)95 & 864 & 816 & 848 & 1.67 & 2.14 & 1.78 \\
\hline (NS2)95 & 919 & 875 & 928 & 1.67 & 2.16 & 1.56 \\
\hline (NS2)95 & 970 & 910 & 977 & 1.67 & 2.29 & 1.45 \\
\hline (NS2)95 & 1009 & 957 & 983 & 1.67 & 2.31 & 2.05 \\
\hline (NS2)95 & 1060 & 1045 & 1081 & 1.67 & 2.31 & 1.75 \\
\hline (NS2)95 & 1109 & 1054 & 1101 & 1.67 & 2.39 & 1.83 \\
\hline (NS2)95 & 1159 & 1114 & 1153 & 1.67 & 2.24 & 1.86 \\
\hline (NS2) 95 & 1241 & 1222 & 1214 & 1.67 & 2.01 & 2.26 \\
\hline (NS2)95 & 1319 & 1308 & 1297 & 1.67 & 1.69 & 1.93 \\
\hline (NS2)90 & 752 & 729 & 738 & 3.33 & 3.07 & 3.43 \\
\hline (NS2)90 & 803 & 824 & 801 & 3.33 & 2.99 & 3.50 \\
\hline (NS2)90 & 856 & 823 & 832 & 3.33 & 3.31 & 3.44 \\
\hline (NS2)90 & 907 & 937 & 939 & 3.33 & 2.89 & 3.09 \\
\hline (NS2) 90 & 953 & 984 & 998 & 3.33 & 2.95 & 2.92 \\
\hline (NS2) 90 & 1001 & 1021 & 1017 & 3.33 & 3.03 & 3.15 \\
\hline (NS2) 90 & 1044 & 1024 & 1069 & 3.33 & $3: 20$ & 2.88 \\
\hline (NS2)90 & 1094 & 1133 & 1094 & 3.33 & 2.88 & 3.47 \\
\hline (NS2)90 & 1146 & 1144 & 1157 & 3.33 & 2.92 & 2.98 \\
\hline (NS2)90 & 1207 & 1236 & 1214 & 3.33 & 2.90 & 3.23 \\
\hline (NS2)80 & 739 & 756 & 747 & 6.67 & 6.63 & 6.76 \\
\hline
\end{tabular}


Table 5.4. (contd)

\begin{tabular}{|c|c|c|c|c|c|c|}
\hline \multirow[b]{3}{*}{ Glass } & \multicolumn{3}{|c|}{ Temperature $\left({ }^{\circ} \mathrm{C}\right)$} & \multicolumn{3}{|c|}{$\mathrm{Al}_{2} \mathrm{O}_{3}(\mathrm{~mol} \%)$} \\
\hline & \multirow[b]{2}{*}{ Actual } & \multicolumn{2}{|c|}{ Calibration Predicted } & \multirow[b]{2}{*}{ Actual } & \multicolumn{2}{|c|}{ Calibration Predicted } \\
\hline & & Classical $^{(\mathfrak{a})}$ & Inverse $^{(\mathbf{b})}$ & & Classical $^{(a)}$ & Inverse $^{(\mathbf{b})}$ \\
\hline (NST2)80 & 793 & 797 & 801 & 6.67 & 6.68 & 6.55 \\
\hline (NS2)80 & 863 & 879 & 869 & 6.67 & 6.79 & 6.82 \\
\hline (NS2)80 & 914 & 919 & 899 & 6.67 & 6.81 & 6.76 \\
\hline (NS2) 80 & 954 & 921 & 919 & 6.67 & 6.98 & 6.70 \\
\hline (NS2)80 & 1006 & 1021 & 993 & 6.67 & 6.86 & 6.75 \\
\hline (NS2)70 & 755 & 792 & 736 & 10.00 & 9.75 & 10.54 \\
\hline (NS2)70 & 809 & 771 & 842 & 10.00 & 10.28 & 9.78 \\
\hline (NS2)70 & 859 & 893 & 882 & 10.00 & 10.02 & 10.10 \\
\hline (NS2)70 & 918 & 898 & 919 & 10.00 & 10.09 & 9.79 \\
\hline$(\mathrm{NS} 2) 70^{(\mathrm{e})}$ & 971 & (e) & (e) & 10.00 & (e) & (e) \\
\hline (NS2)70 & 1022 & 1088 & 1018 & 10.00 & 10.10 & 9.78 \\
\hline (NS2)70 & 1082 & 1131 & 1073 & 10.00 & 9.77 & 9.70 \\
\hline $\mathbf{R}^{2}$ & & 0.951 & 0.982 & & 0.990 & 0.994 \\
\hline \multicolumn{7}{|c|}{$\begin{array}{l}\text { (a) Nine of the Table } 5.3 \text { calibration equations (described in Eq. [5.2]) expressing the } \\
\text { Raman parameters as functions of temperature (T) and } \mathrm{Al}_{2} \mathrm{O}_{3}(\mathrm{x}) \text { were } \\
\text { simultaneously solved for } \mathrm{T} \text { and } \mathrm{x} \text { for each data point. } \\
\text { (b) Predictions obtained from the calibration equations in Table } 5.5 \text {. } \\
\text { (c) Estimates of } \mathrm{Al}_{2} \mathrm{O}_{3} \text { were constrained to be nonnegative in the nonlinear least squares } \\
\text { estimation software. } \\
\text { (d) Predicted value was negative in the range }-0.45 \text { to } 0.00 \text {, and thus changed to zero. } \\
\text { (e) Judged to be an outlier and not used in developing or assessing the calibration } \\
\text { equations. }\end{array}$} \\
\hline
\end{tabular}

$\mathrm{a}_{1050}$, and $\mathrm{a}_{1100}$. The parameters $\mathrm{F}_{900}$ and $\mathrm{W}_{900}$ were not used because of missing or zero values for the (NS2) 100 glass, and $a_{950}$ was not used because of the linear mixture constraint among the peak proportional areas. ${ }^{\text {(a) }}$ The calibration equations for $\mathrm{T}$ (temperature, $\left.{ }^{\circ} \mathrm{C}\right)$ and $\mathrm{x}\left(\mathrm{Al}_{2} \mathrm{O}_{3}\right.$, mol\% $)$ resulting from this approach are linear combinations of the best subsets of Raman parameters. The coefficients of the best subset linear combinations for $\mathrm{T}$ and $\mathrm{x}$ are given in Table 5.5.

(a) The proportional areas satisfy a mixture constraint, namely $a_{900}+a_{950}+a_{1050}+a_{1100}=1$. This constraint caused problems for the software algorithm used to perform all-subsets regression. Hence, $a_{950}$ was removed because of its poorer correlation with glass composition and temperature compared to the other $a_{\mathrm{i}}$ values. 


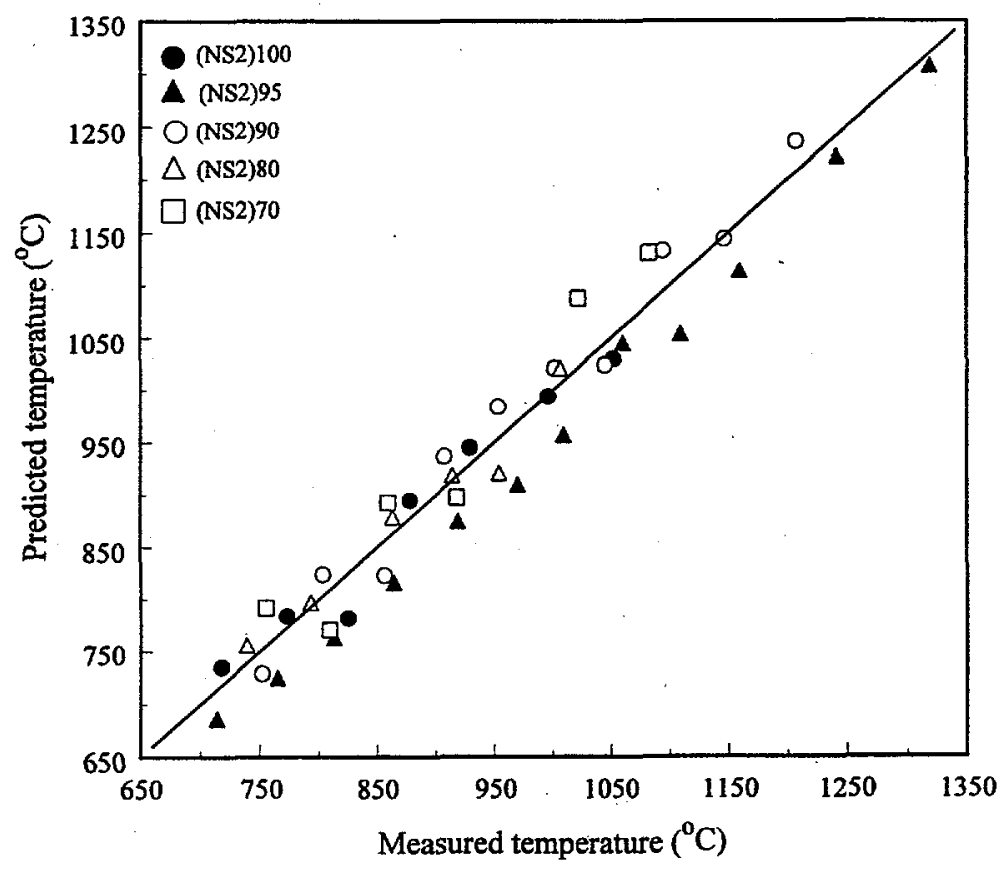

Figure 5.1. Predicted Versus Measured Plot for Classical Calibration Equations Relating Glass Melt Temperature $\left({ }^{\circ} \mathrm{C}\right)$ to Raman Parameters

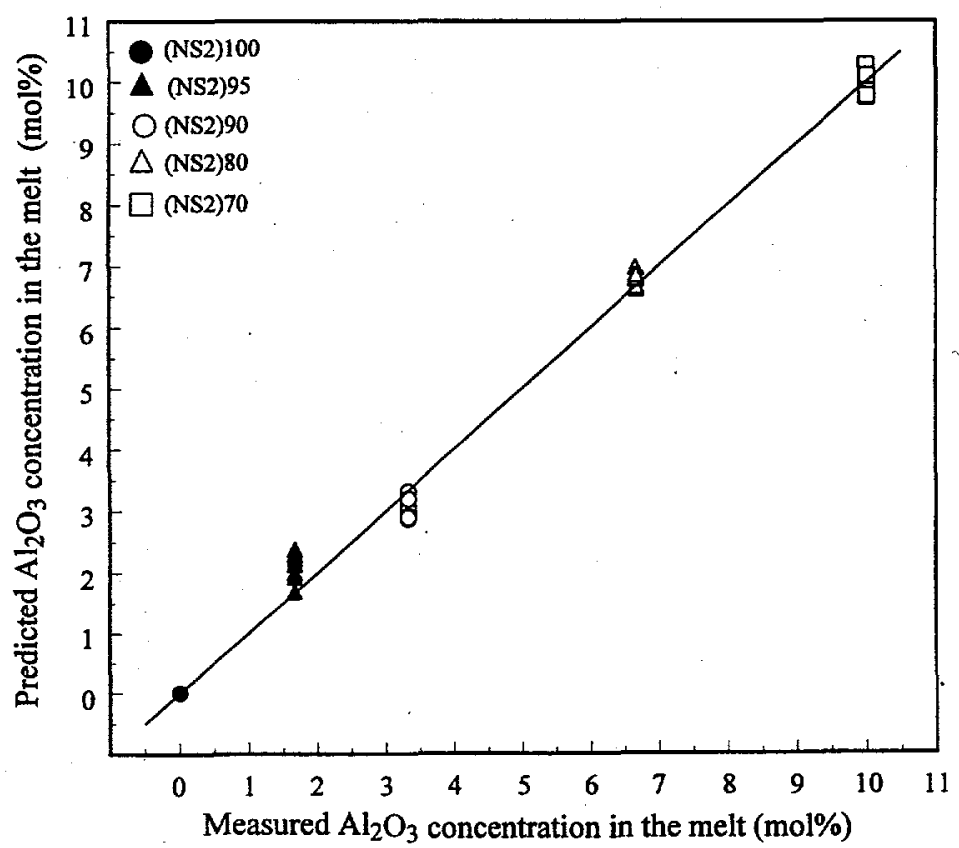

Figure 5.2. Predicted Versus Measured Plot for Classical Calibration Equations Relating Glass Composition (Represented by $\mathrm{Al}_{2} \mathrm{O}_{3} \mathrm{~mol} \%$ ) to Raman Parameters 
Table 5.5 shows that $\mathrm{F}_{950}, \mathrm{~F}_{1050}, \mathrm{~W}_{950}, \mathrm{~W}_{1100}$, and $\mathrm{a}_{1100}$ appear in the calibration equations for $\mathrm{T}$ and $\mathrm{x}$, and that the equation for $x$ also contains $W_{1050}$. The $\mathrm{R}^{2}$ values for the $\mathrm{T}$ and $\mathrm{x}$ equations are 0.982 and 0.994 , respectively. These values are the proportions of variations in $\mathrm{T}$ and $\mathrm{x}$ values accounted for by the calibration equations. The $\mathrm{R}^{2}$ values for the inverse calibration approach are slightly larger than those obtained earlier for the classical calibration approach. This was expected, since the inverse calibration. approach involves directly fitting $\mathrm{x}$ and $\mathrm{T}$, rather than predicting them indirectly via "inverting" classical calibration equations. However, as noted in Appendix A, the two approaches are not equal in terms of underlying statistical theory. It is beyond the scope of this effort to delve further into comparisons of the two approaches.

Table 5.5 Fitted Inverse Calibration Equations for Mysen and Frantz Data (1994b)

\begin{tabular}{|c|c|c|}
\hline \multirow[b]{2}{*}{ Raman Parameter } & \multicolumn{2}{|c|}{$\begin{array}{l}\text { Coefficients for Inverse Calibration } \\
\text { Equations }\end{array}$} \\
\hline & $\mathbf{T}\left({ }^{\circ} \mathbf{C}\right)$ & $\mathrm{x}\left(\mathrm{Al}_{2} \mathrm{O}_{3}, \mathrm{~mol} \%\right)$ \\
\hline Constant & 20279.787 & 3.7111 \\
\hline$F_{950}$ & -40.515 & 0.2153 \\
\hline$F_{1050}$ & 17.611 & -0.2161 \\
\hline$F_{1100}$ & (a) & (a) \\
\hline$W_{950}$ & -15.013 & 0.4085 \\
\hline$W_{1050}$ & (a) & 0.1292 \\
\hline$W_{1100}$ & 31.368 & -0.2472 \\
\hline$a_{900}$ & (a) & (a) \\
\hline$a_{1050}$ & (a) & (a) \\
\hline$a_{1100}$ & -3041.673 & 28.1665 \\
\hline \multicolumn{3}{|c|}{ Goodness-of-Fit Statistics } \\
\hline$R^{2(b)}$ & 0.982 & 0.994 \\
\hline$s^{(c)}$ & 21.58 & 0.2741 \\
\hline \multicolumn{3}{|c|}{$\begin{array}{l}\text { (a) This Raman parameter was not selected for inclusion in the equation } \\
\text { (i.e., its coefficient is zero). } \\
\text { (b) } \mathrm{R}^{2} \text { represents the proportion of variation in the response variable ( } T \text { or } \\
\mathrm{x} \text { ) accounted for by the fitted equation. As such, } 0 \leq \mathrm{R}^{2} \leq 1 \text {. } \\
\text { (c) The statistic "s" represents an estimate of the prediction error standard } \\
\text { deviation in the response variable ( } \mathrm{T} \text { or } \mathrm{x} \text { ). }\end{array}$} \\
\hline
\end{tabular}


The predicted $\mathrm{T}$ and $\mathrm{x}$ values for this "inverse calibration" approach are listed next to "measured" values for each data point in Table 5.5. The predicted values for the "classical calibration" approach are also contained in Table 5.5, as discussed earlier. Figures 5.3 and 5.4 display the predicted versus measured plots for the fitted $\mathrm{T}$ and $\mathrm{x}$ inverse calibration equations, respectively. Each of the two plots has a relatively tight scatter around the $45^{\circ}$ line that represents perfect prediction. Overall, the calibration equations appear to provide a good fit, and thus good predictions for the data used to develop the equations. Similar to Figures 5.1 and 5.2, Figures 5.3 and 5.4 show a tendency to over-predict $\mathrm{Al}_{2} \mathrm{O}_{3}$ mol\% for the (NS2) 95 glass, and under-predict $\mathrm{Al}_{2} \mathrm{O}_{3}$ mol\% for the (NS2) 90 glass.

Ultimately, the performance of calibration equations must be assessed (validated) using data different from the data used to develop the equations. However, there are no separate data for this glass system that can be used to validate the calibration equations in Table 5.5. Instead, a cross-validation method was employed wherein each data point was in turn withheld from the data set, the inverse calibration equations refitted, and predictions made for the withheld data points. ${ }^{(a)}$ The resulting cross-validation $R^{2}$ $\left(\mathrm{R}^{2} \mathrm{CV}\right)$ values are 0.976 for $T$, and 0.991 for $\mathrm{x}\left(\mathrm{Al}_{2} \mathrm{O}_{3}\right)$. These values are very close to the fitted $\mathrm{R}^{2}$ values in Table 5.5, indicating very good cross-validation performance of the inverse calibration equations.

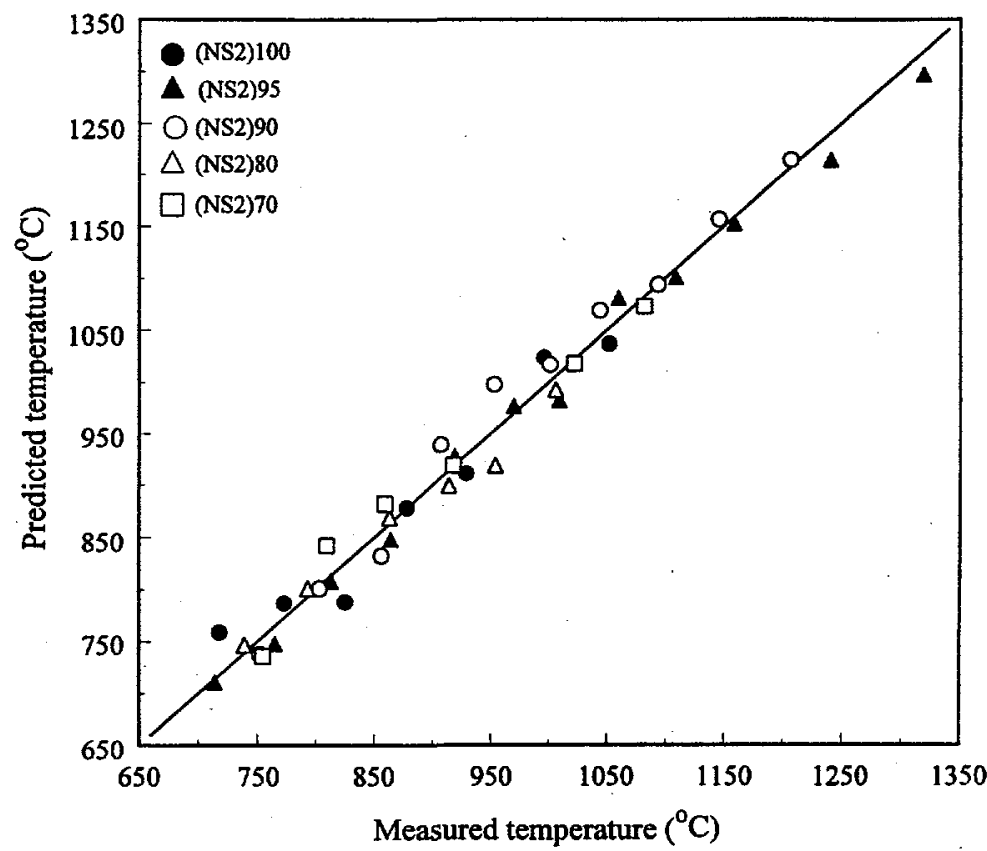

Figure 5.3. Predicted Versus Measured Plot for Inverse Calibration Equations Relating Glass Melt Temperature $\left({ }^{\circ} \mathrm{C}\right)$ to Raman Parameters

(a) A special formula allows calculating predicted values for withheld data points without refitting the equations for each withheld data point. 


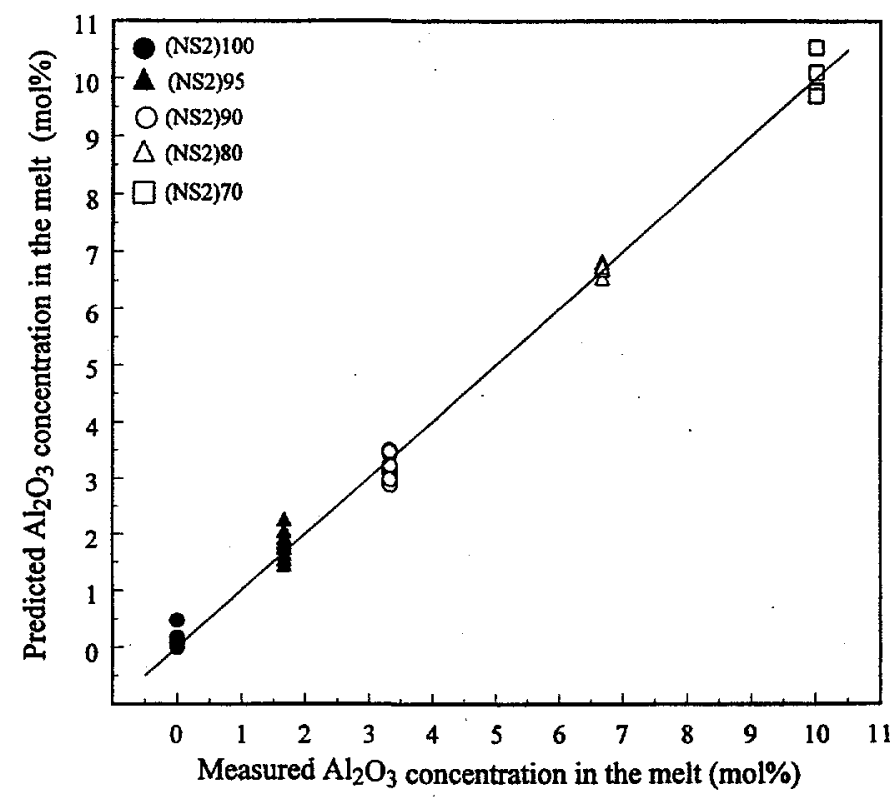

Figure 5.4. Predicted Versus Measured Plot for Inverse Calibration Equations Relating Glass Composition (Represented by $\mathrm{Al}_{2} \mathrm{O}_{3}$ mol\%) to Raman Parameters

However, applying the calibration equations to data from new glasses with Raman measurements taken at a different time would likely result in more decrease in validation $R^{2}$ values compared to the fitted $R^{2}$ values.

\subsection{Comments on Statistical Multivariate Calibration}

In Sections 5.1 and 5.2, statistical multivariate calibration methods were applied to data sets involving frequency, FWHM, and proportional area parameters obtained from fitting overlapping Gaussian peaks to Raman spectra. The process of fitting overlapping peaks is part "science" and part "art", and is time-consuming. The process can also be subject to considerable uncertainty because there can be multiple ways to fit overlapping peaks that give approximately equivalent fits to the whole spectrum.

In the field of chemometrics (statistics applied to chemistry and analytical chemistry problems), multivariate calibration is typically performed directly on appropriately pre-processed spectral data, without applying the peak fitting process. In our situation, the Raman intensities would have to be temperature corrected (as described in Section 4.1), and baseline-corrected as is done currently as part of the peakfitting process (as described in Section 4.2). The Raman intensities would also have to be normalized in an appropriate way to adjust for setup and environmental differences. Other pre-processing steps may also be needed (see Chapter 3 of Beebe et al. 1998). 
Then, multivariate calibration methods could be applied directly to the pre-processed intensities, skipping the time-consuming and prone-to-uncertainty step of peak fitting for each combination of glass composition and temperature. This simplification may be especially valuable in the future as complicated, multicomponent glasses are studied. 


\subsection{Conclusions}

In the past, high-temperature Raman measurements using a continuous wave laser with 488- and 514-nm excitation lines were performed only on glass thin films to minimize black-body radiation interferences. Continuous-wave laser excitation with a 488-nm excitation line was shown by this study to work at temperatures below $900^{\circ} \mathrm{C}$ for bulk quantities of glass. A pulse-gating Raman setup was developed in this project to minimize black-body radiation interferences on high-temperature Raman spectra. The pulse-gating Raman setup provides on-line Raman measurements for glasses at temperature as high as $1412^{\circ} \mathrm{C}$. Comparisons were made between the high-temperature Raman data collected from this study and data reported in the literature. The results suggest that an optimization of the pulse-gating Raman setup is necessary to further improve data quality (i.e., to obtain data with a higher signal-to-noise ratio).

An UV confocal Raman microspectrometer with continuous-wave laser excitation at $325 \mathrm{~nm}$ was evaluated selectively using a transparent silicate glass and a deep-colored high-level waste glass in a bulk quantity. Raman data were successfully collected at temperatures as high as approximately $1500^{\circ} \mathrm{C}$. The results demonstrated that the UV excitation laser can be used for high-temperature Raman measurements of molten glasses without black-body radiation interferences. Considering operational reliability and efficiency, an UV confocal Raman microspectrometer is recommended for developing hightemperature glass databases that can be utilized to generate reliable statistical models. UV lasers with excitation lines 325 and $244 \mathrm{~nm}$ are available for UV confocal Raman microspectrometers. Further studies are needed to select the best laser system.

Statistical models, based on classical calibration and inverse calibration statistical methods, were developed using high-temperature data reported in the literature for sodium-alumino-silicate glasses. Within the composition and temperature regimes for which the models were developed, the predicted values for temperature or glass composition (in terms of $\mathrm{Al}_{2} \mathrm{O}_{3}$ for this literature data set) agree very well with their corresponding, measured values. $\mathrm{R}^{2}$ values for the classical and inverse calibration approaches were 0.951 and 0.982 , respectively, for melt temperature, and 0.990 and 0.995 , respectively, for glass composition $\left(\mathrm{Al}_{2} \mathrm{O}_{3}\right.$ concentration).

Based on the results of the Phase I work, an OMMS, composed of high-temperature Raman spectrometer and statistical models involving mathematical functions of Raman parameters, melt temperature, and melt composition, has been demonstrated to be feasible for on-line glass process control. The combination of improved high-temperature Raman spectroscopy technology and reliable statistical models are envisioned to have potential applications for next-generation, integrated on-line process control systems for commercial glass industry and radioactive waste glass vitrification facilities. 


\subsection{References}

Beebe, K. R., R. J. Pell, and M. B. Seasholtz. 1998. Chemometrics: A Practical Guide (John Wiley and Sons, New York).

Brawer, S. A. and W. B. White. 1975. "Raman Spectroscopic Investigation of the Structure of Silicate Glasses, I, The Binary Silicate Glasses," J. Phys. Chem. Glasses, 63:2421-2432.

Brawer, S. A. and W. B. White. 1977. "Raman Spectroscopic Investigation of the Structure of Silicate Glasses, II, Soda-Alkaline Earth-Alumina Ternary and Quaternary Glasses," J. Non Cryst. Solids, 23:261-278.

Bunker, B. C., D. R. Tallant, R. J. Kirkpatrick, and G. L. Turner. 1990. "Multinuclear Magnetic Resonance and Raman Investigation of Sodium Borosilicate Glass Structures," Phy. Chem. Glasses, 31:30-41.

Furukawa, T. and W. B. White. 1981. "Raman Spectroscopic Investigation of Sodium Borosilicate Glass Structure," J. Mater. Sci., 16:2689-2700.

Hrma, P., G. F. Piepel, M. J. Schweiger, D. E. Smith, D. S. Kim, P. E. Redgate, J. D. Vienna, C. A. LoPresti, D. B. Simpson, D. K. Peeler, and M. H. Langowski. 1994. Property/Composition Relationships for Hanford High-Level Waste Glass Melting at $1150^{\circ} \mathrm{C}$, PNL-10359, Pacific Northwest National Laboratory, Richland, Washington.

McMillan, P., B. Ririou, and A. Navrotsky. 1982. "A Raman Study of Glasses Along the Joints SilicaCalcium Aluminate, Silica-Sodium Aluminate, and Silica-Potassium Aluminate," Geochim. et Cosmochim. Acta 46:2021-2037.

McMillan, P. 1984. "Structural Studies of Silicate Glasses and Melt-Applications and Limitations of Raman Spectroscopy," Am. Mineral. 69:622-644.

Marquart, D. W. 1963. "An Algorithm for Least Squares Estimation of Nonlinear Parameters," J. Soc. Ind. Appl. Math., 11:431-441.

Martens, H. and T. Naes. 1989. Multivariate Calibration (John Wiley and Sons, New York).

Mysen, B. O., D. Virgo, and I. Kushiro. 1981. "The Structural Role of Aluminum in Silicate Melts - A Raman Spectroscopic Study at 1 Atmosphere," Am. Mineral. 66:678-701.

Mysen, B. O., L. W. Finger, D. Virgo, and F. A. Seifert. 1982. "Curve-fitting of Raman Spectra of Silicate Glasses," Am. Miner. 67:686-695. 
Mysen, B. O. and J. D. Frantz. 1993. "Structure of Silicate Melts at High Temperature: In-situ Measurements in the System $\mathrm{BaO}-\mathrm{SiO}_{2}$ to $1669^{\circ} \mathrm{C}$," Am. Mineral. 78:699-709.

Mysen, B. O. and J. D. Frantz. 1993. "Structure and Properties of Alkali Silicate Melts at Magmatic Temperatures," European J. Mineral., 5:393-407.

Mysen, B.O. and J.D. Frantz. 1994a. "Silicate Melts at Magmatic Temperatures: In-Situ Structure Determination to $1651^{\circ} \mathrm{C}$ and Effect of Temperature and Bulk Composition on the Mixing Behavior of Structural Units," Contrib Mineral Petrol, 117:1-14.

Mysen, B. O. and J. D. Frantz. 1994b. "Structure of Haplobasaltic Liquids at Magmatic Temperatures: In Situ, High-Temperature Study of Melts on the Join $\mathrm{Na}_{2} \mathrm{Si}_{2} \mathrm{O}_{5}-\mathrm{Na}_{2}(\mathrm{NaAl})_{2} \mathrm{O}_{5}$," Geochim. et Cosmochim. Acta, 58:1711-1733.

Mysen, B. O. 1995. "Structural Behavior of $\mathrm{Al}^{3+}$ in Silicate Melts: In Situ, High-Temperature Measurements as a Function of Bulk Chemical Composition," Geochim. et Cosmochim. Acta, 59:455-474.

Neuville, D. R. and B. O. Mysen. 1996. "Role of Aluminum in the Silicate Network: In- Situ, HighTemperature Study of Glasses and Melts on the Join $\mathrm{SiO}_{2}-\mathrm{NaAlO}_{2}$," Geochim. et Cosmochim. Acta, 60:1727-1737.

Saniel, I., P. Gillet, B. T. Poe, and P. F. McMillan. 1995. "In-Situ High-Temperature Raman Spectroscopic Studies of Aluminosilicate Liquids," Phys. Chem. Minerals, 22:74-86.

Seifert, F. A., B. O. Mysen, and D. Virgo. 1981. "Structural Similarity of Glass and Melts Relevant to Petrological Processes," Geochim. Cosmochim: Acta 45:1879-1884.

U.S. Department of Energy, Office of Environmental Management. 1996. Waste Acceptance Product Specifications for Vitrified High-Level Waste Forms, EM-WAPS Rev. 02.

Walrafen, G. E., M. R. Fisher, M. S. Hokmabadi, and W. H. Yang. 1986. "Temperature Dependence of the Low- and High-Frequency Raman Scattering from Liquid Water," J. Chem. Phys., 85:6970-6982. 
Appendix A

Statistical Multivariate Calibration 


\section{Appendix A}

\section{Statistical Multivariate Calibration}

Statistical multivariate calibration involves a two-step process. In the first step, a "training" data set is collected from which calibration equations are developed. In the case covered in this report, the calibration equations relate measured Raman parameters to "known" melt temperatures and glass compositions. Then, in the second step, the calibration equations are used to estimate unknown variables of interest (melt temperature and glass composition in this case) from the measured variables (Raman parameters). Because statistical calibration methods are used, uncertainties and confidence statements can be made regarding the estimated variables. However, uncertainties and confidence statements are not addressed in this report, because of the "feasibility study" nature of this initial work.

Various "regression-type" methods are available to develop multivariate calibration equations, including: multiple least squares regression (MLSR), principal components regression (PCR), partial least squares regression (PLS), and several other methods. It is beyond the scope of this report to explain these methods. We refer the reader to Martens and Naes (1989), Beebe et al. (1998), or other references for the details of multivariate calibration methods.

Regardless of the regression-type method used, it must be decided which variables are to be the regressor variables, and which are to be the response variables. It is assumed for discussion purposes here that there are at least two regressor variables (denoted $\mathrm{X}$ ) and at least two response variables (denoted Y).

In the classical calibration approach using MLSR, X variables are assumed to be known without uncertainty (or with uncertainty that is small compared to the uncertainty of the $Y$ variables). The $Y$ variables are then regressed on the $X$ variables to yield the calibration equations. However, in practice, the calibration equations must be used to estimate $X$ given measured values of $Y$. This means that the calibration equations must be "inverted", i.e., solved for the $X$ variables in terms of the $Y$ variables. There may not be closed form solutions for the $\mathrm{X}$ variables as functions of the $\mathrm{Y}$ variables, and there are complicating factors in dealing with the uncertainty of estimated $\mathrm{X}$ variables.

Alternatively, the calibration problem can be addressed by what is referred to as inverse calibration, regressing the $\mathrm{X}$ variables on the $\mathrm{Y}$ variables. This approach avoids the "inversion step" required in the classical approach to calibration. In the case where the $X$ variables have little or no uncertainty compared to the $Y$ variables, this approach violates the traditional assumptions of least squares regression. However, this approach often works well in practice. Statistical measurement error model methods can be applied to avoid the violation of traditional regression modeling assumptions, but doing so is not addressed in this report. 
Appendix B

\section{Plots of PNNL Pulse-Gating Raman Measurement Results}




\section{Appendix B}

\section{Plots of PNNL Pulse-Gating Raman Measurement Results}

The Raman data from PNNL measurement of three sodium-silicate glasses summarized in Table 4.1 is plotted in this appendix. Figures B.1 to B.3 contain plots of Raman parameters (peak frequencies, peak FWHMs, and peak proportional areas) versus temperature, while Figures B.4 to B.6 contain plots of these Raman parameters versus $\mathrm{Na}_{2} \mathrm{O}$ contents of the glasses. In Figures B.1 to B.3, different plotting symbols are used to represent the $\mathrm{Na}_{2} \mathrm{O}$ contents of the three glasses tested. In Figures B.4 to B.6, the temperature values corresponding to each data point appear on the plot next to the data points. 

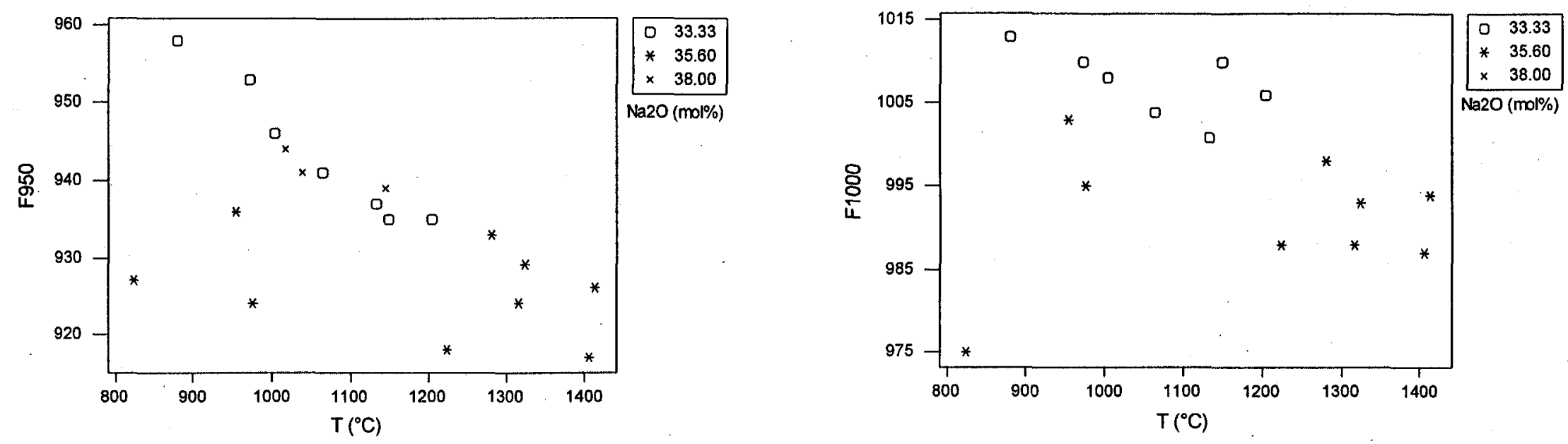

$\underset{\sim}{\infty}$

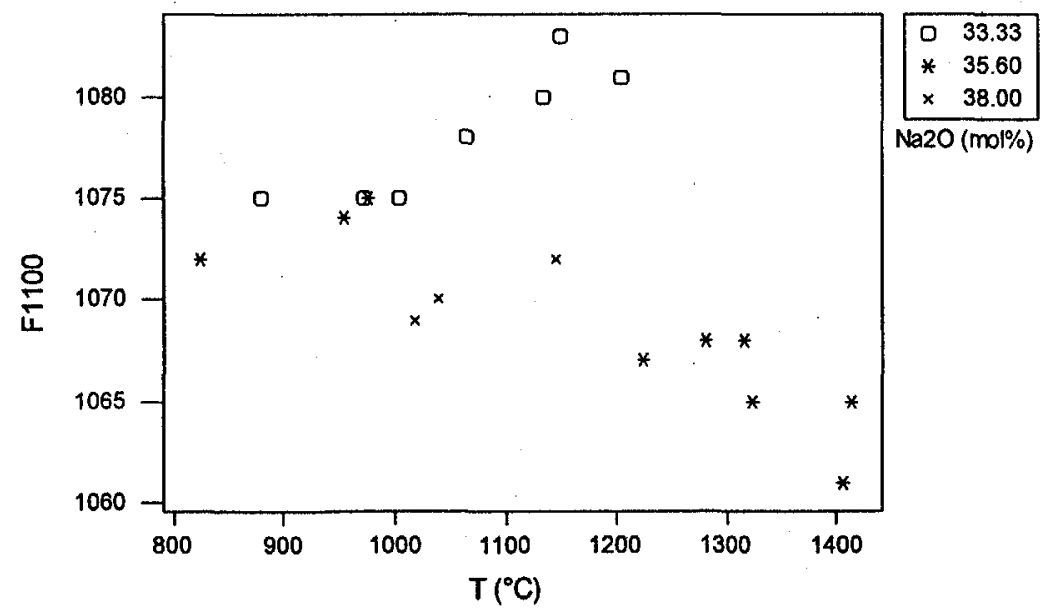

Figure B.1. PNNL $\mathrm{xNa}_{2} \mathrm{O}(1-\mathrm{x}) \mathrm{Si}_{2} \mathrm{O}$ Raman Fitted Peak Frequencies at 950,1000 , and $1100 \mathrm{~cm}^{-1}$ Versus Temperature 


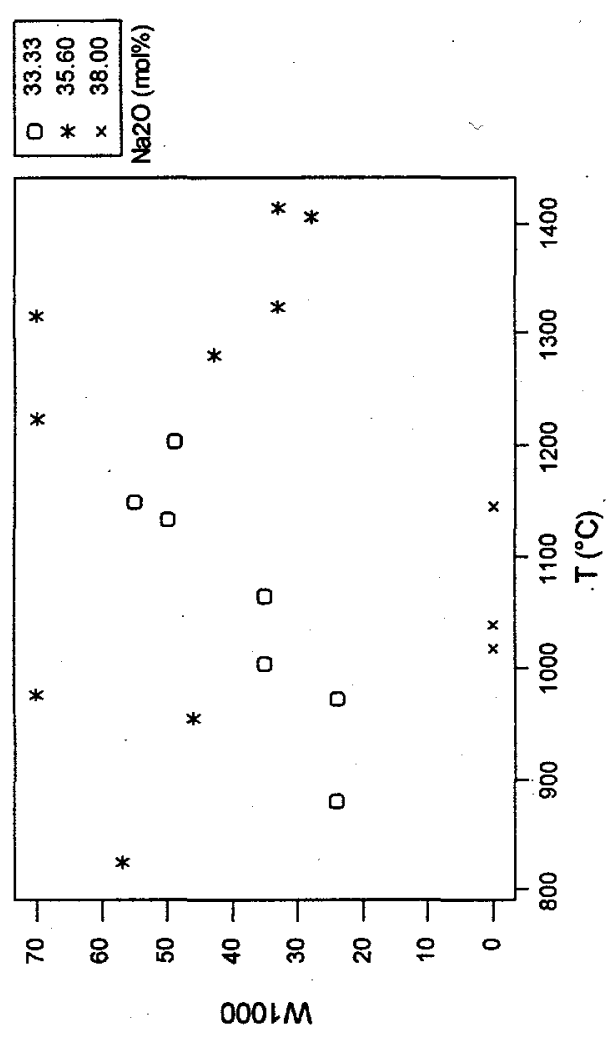

总
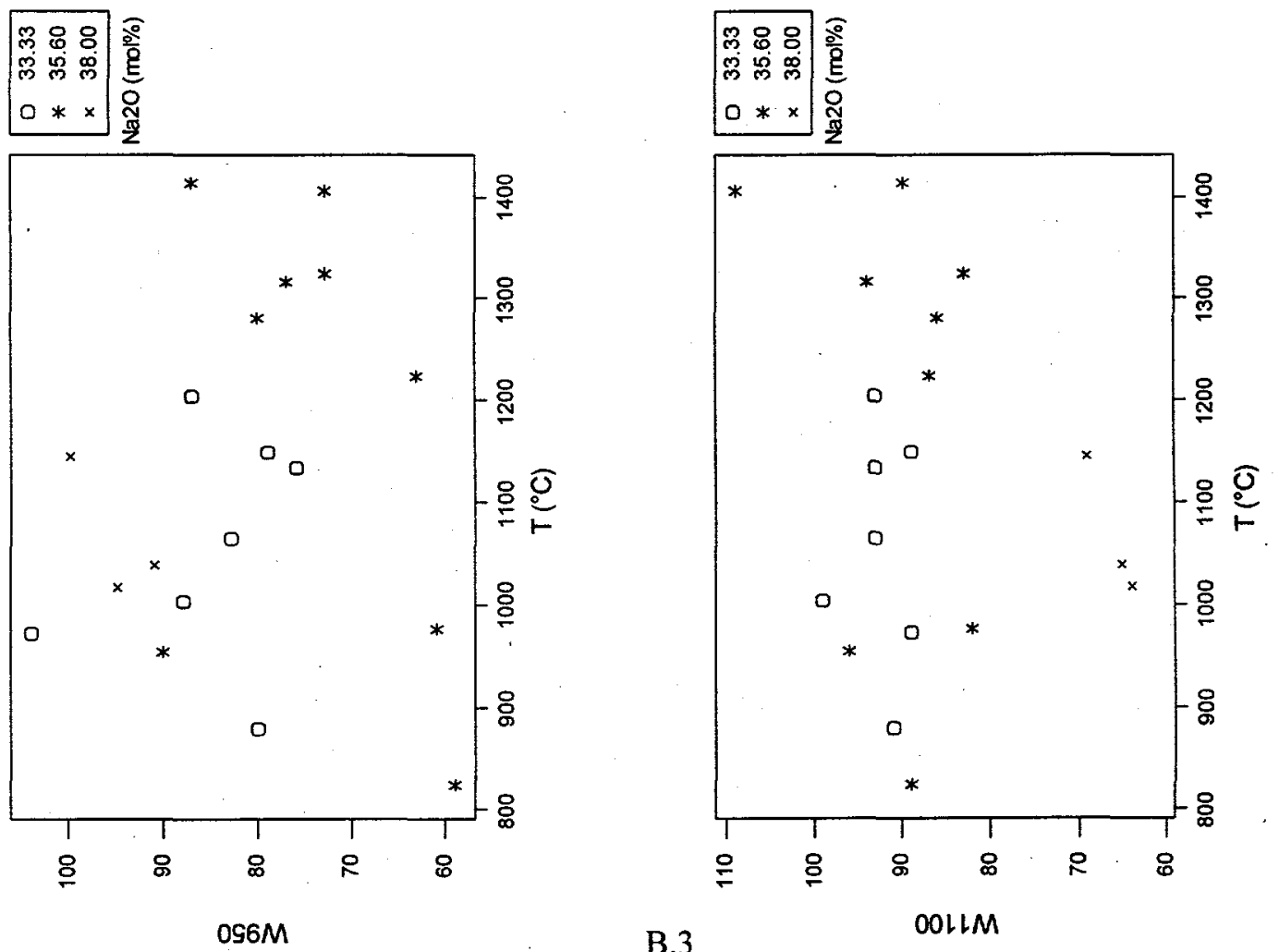

B. 3 

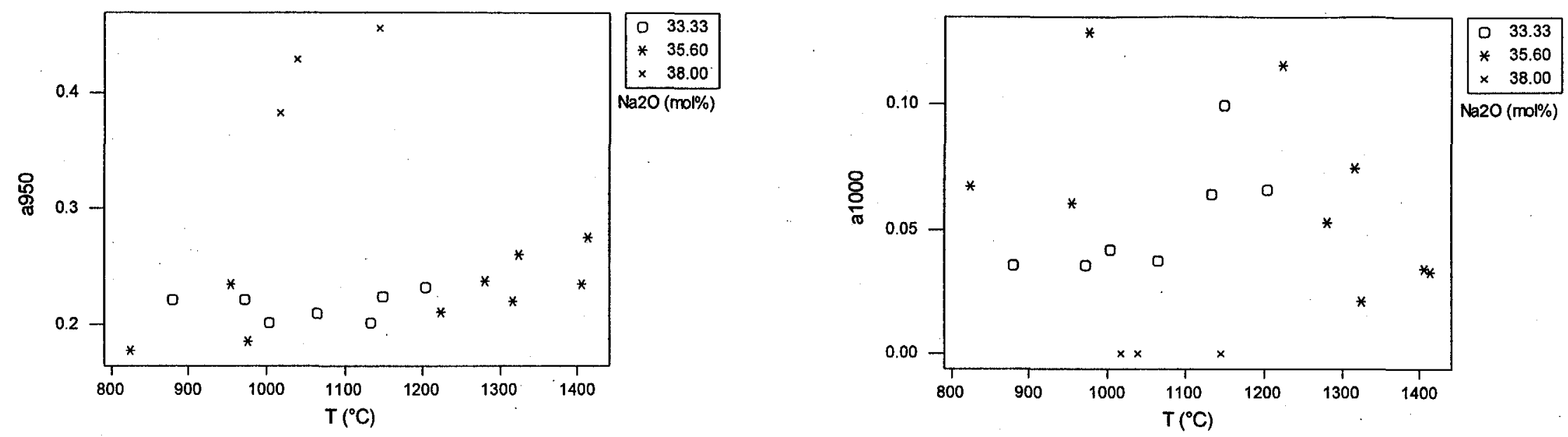

$\underset{\square}{\longrightarrow}$

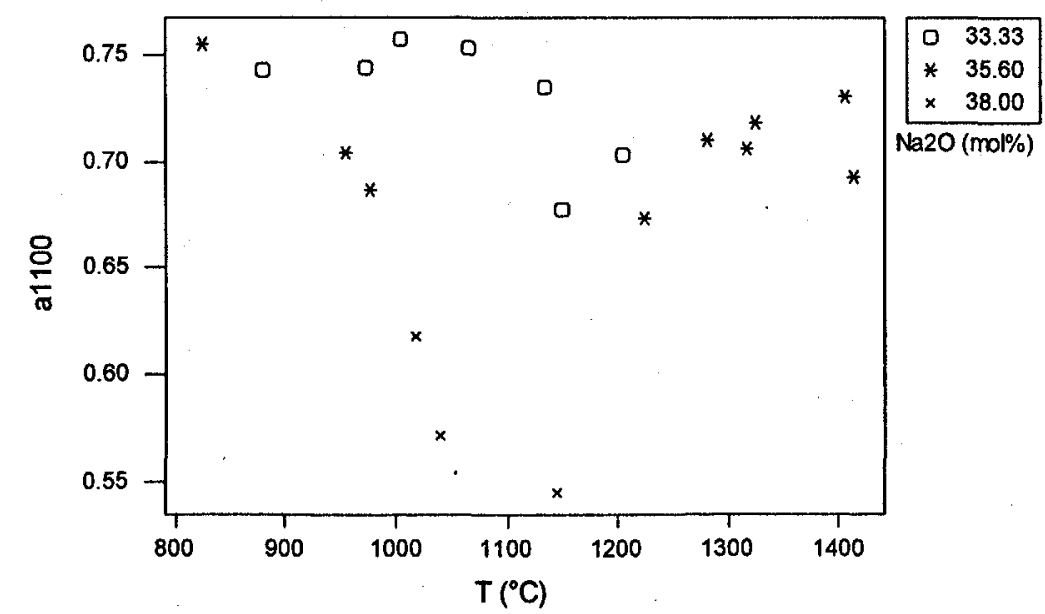

Figure B.3. PNNL xNa $\mathrm{Pa}_{2} \mathrm{O}(1-\mathrm{x}) \mathrm{Si}_{2} \mathrm{O}$ Raman Fitted Peak Proportional Areas at 950,1000 , and $110.0 \mathrm{~cm}^{-1}$ Versus Temperature 

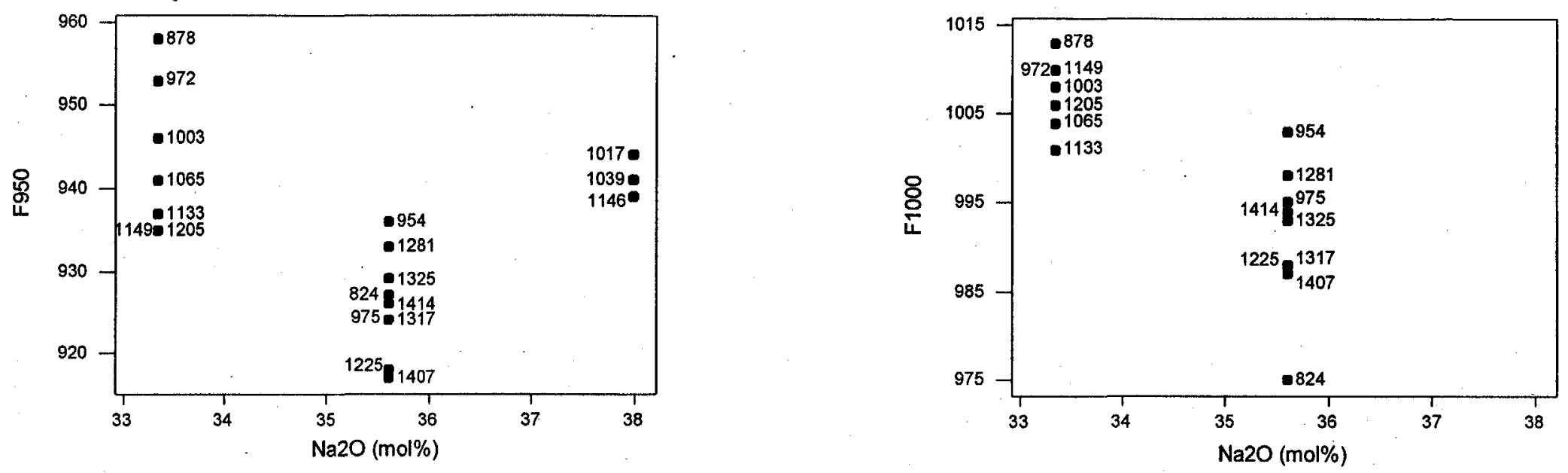

is

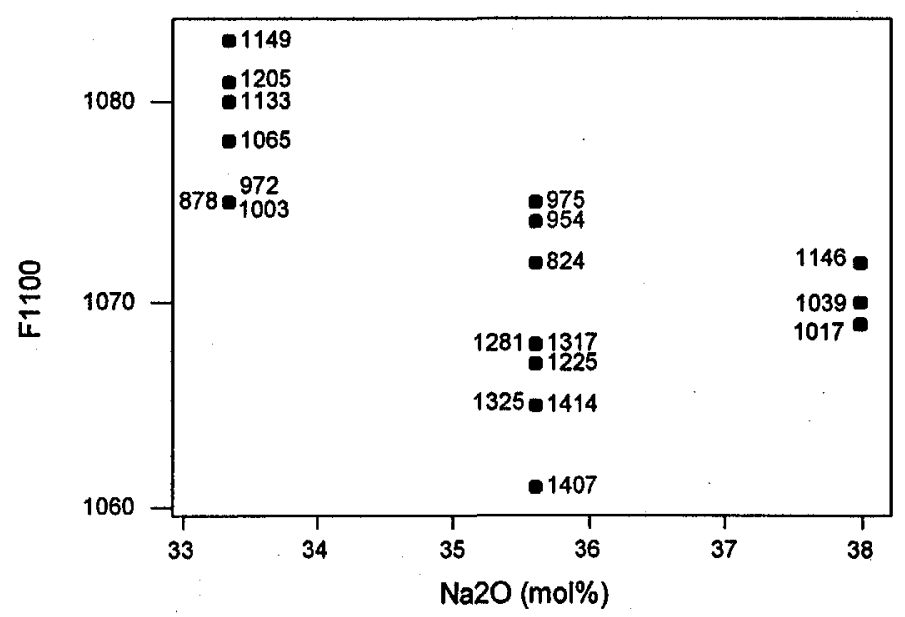

Figure B.4. PNNL $x \mathrm{Na}_{2} \mathrm{O}(1-\mathrm{x}) \mathrm{Si}_{2} \mathrm{O}$ Raman Fitted Peak Frequencies at 950, 1000, and $1100 \mathrm{~cm}^{-1}$ Versus $\mathrm{Na}_{2} \mathrm{O}(\mathrm{mol} \%)$, With Temperature $\left({ }^{\circ} \mathrm{C}\right)$ Values Next to Data Points 


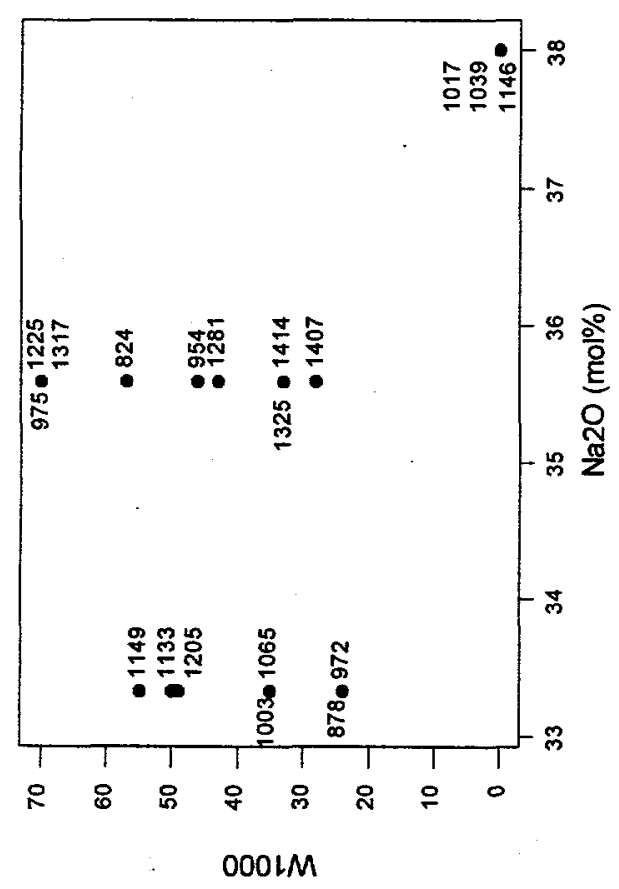

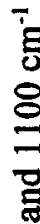

8

용

䒕 营

के

齐

$z$

을

잉

寻

(

늘

氖

을

สี อ

코
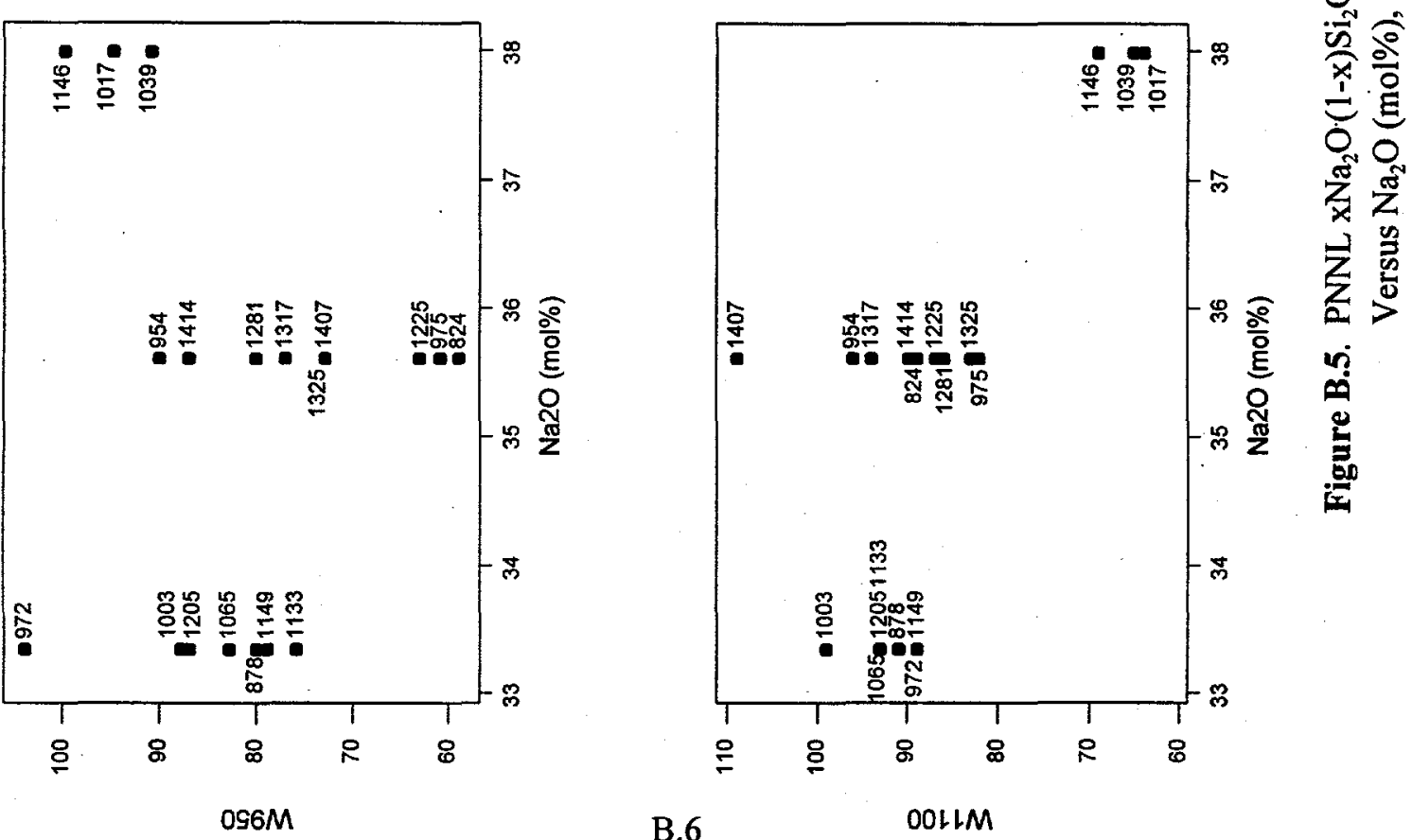

B. 6

OOLLM 

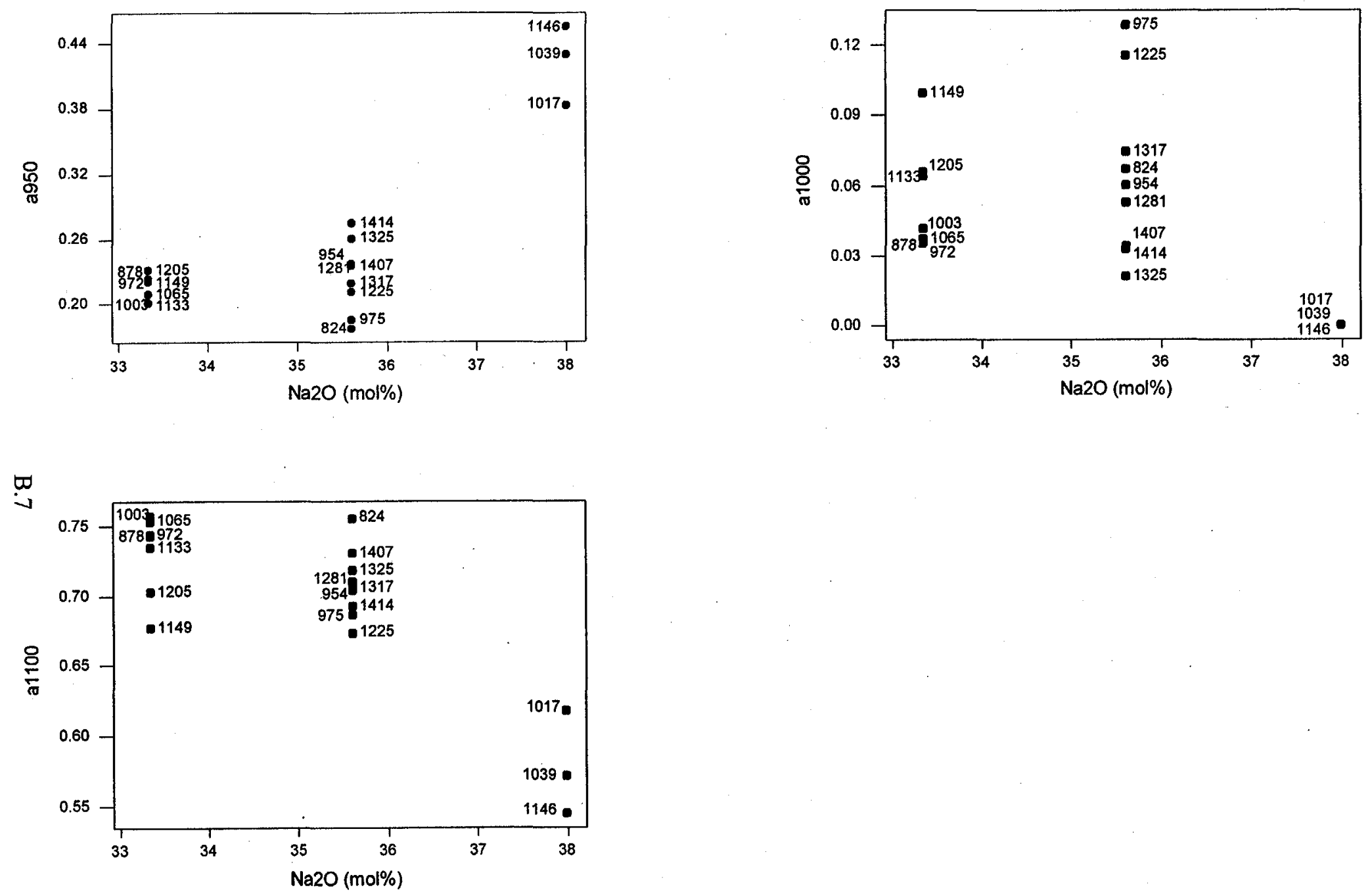

Figure B.6. PNNL $x \mathrm{Na}_{2} \mathrm{O} \cdot(1-\mathrm{x}) \mathrm{Si}_{2} \mathrm{O}$ Raman Fitted Peak Proportional Areas at 950,1000 , and $1100 \mathrm{~cm}^{-1}$ Versus $\mathrm{Na}_{2} \mathrm{O}$ (mol\%), With Temperature $\left({ }^{\circ} \mathrm{C}\right)$ Values Next to Data Points 


\section{Appendix C}

Plots of Mysen and Frantz (1994b) Raman Data Used in Modeling 


\section{Appendix C}

\section{Plots of Mysen and Frantz (1994b) Raman Data Used in Modeling}

The Raman data from Mysen and Frantz's (1994b) measurement of five sodium-alumino-silicate glasses summarized in Table 5.2 is plotted in this appendix. Figures C. 1 to C. 3 contain plots of Raman parameters (peak frequencies, peak FWHMs, and peak proportional areas) versus temperature, while Figures C. 4 to C. 6 contain plots of these Raman parameters versus $\mathrm{Al}_{2} \mathrm{O}_{3}$ contents (mol\%) of the glasses. Although sodium-alumino-silicate glasses were studied, they were obtained as binary mixtures of $\mathrm{Na}_{2} \mathrm{Si}_{2} \mathrm{O}_{5}$ and $\mathrm{Na}_{2}(\mathrm{NaAl})_{2} \mathrm{O}_{5}$. Hence, only a single variable is needed to represent composition changes, and $\mathrm{Al}_{2} \mathrm{O}_{3}$ was selected.

In Figures C.1 to C.3, different plotting symbols are used to represent the $\mathrm{Al}_{2} \mathrm{O}_{3}$ contents of the five glasses tested. In Figures C. 4 to C.6, the temperature values corresponding to each data point do not appear as they did in Appendix B. This is because of the lack of space resulting from the larger number of data points in the plots.

Figures C. 3 and C.6 show that the Mysen and Frantz (1994b) fitted peaks for the (NS2)95 glasses (with $1.67 \mathrm{~mol} \% \mathrm{Al}_{2} \mathrm{O}_{3}$ ) have proportional areas not matching the trends indicated by the other glasses. Such results are fairly common, due to the uncertainties involved in fitting overlapping peaks where the measured data are subject to considerable uncertainty. 

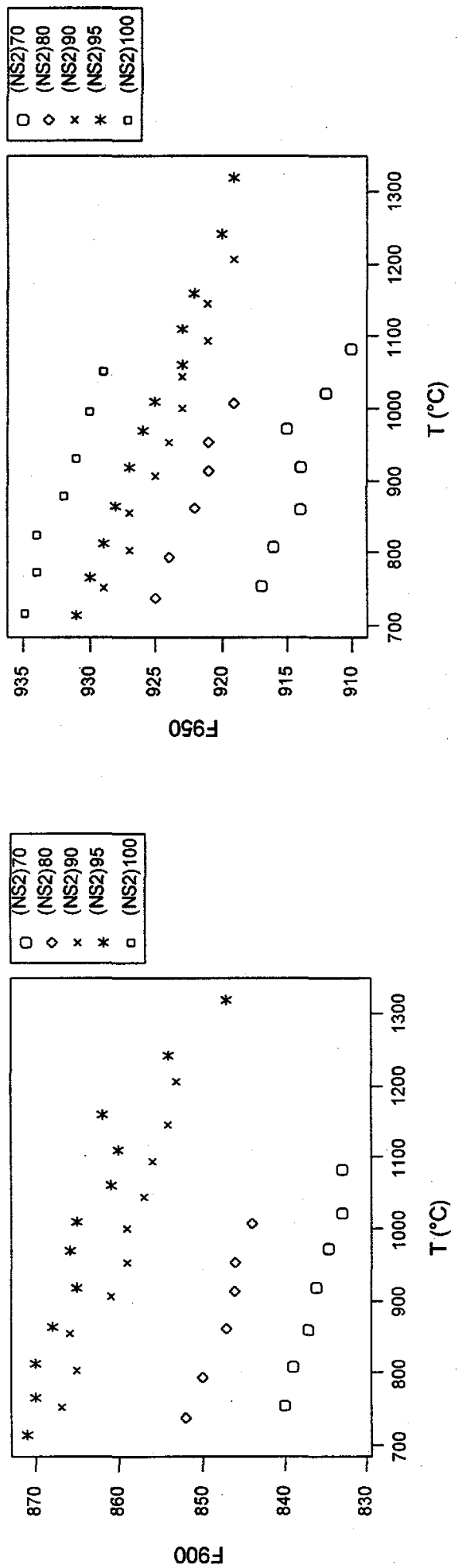
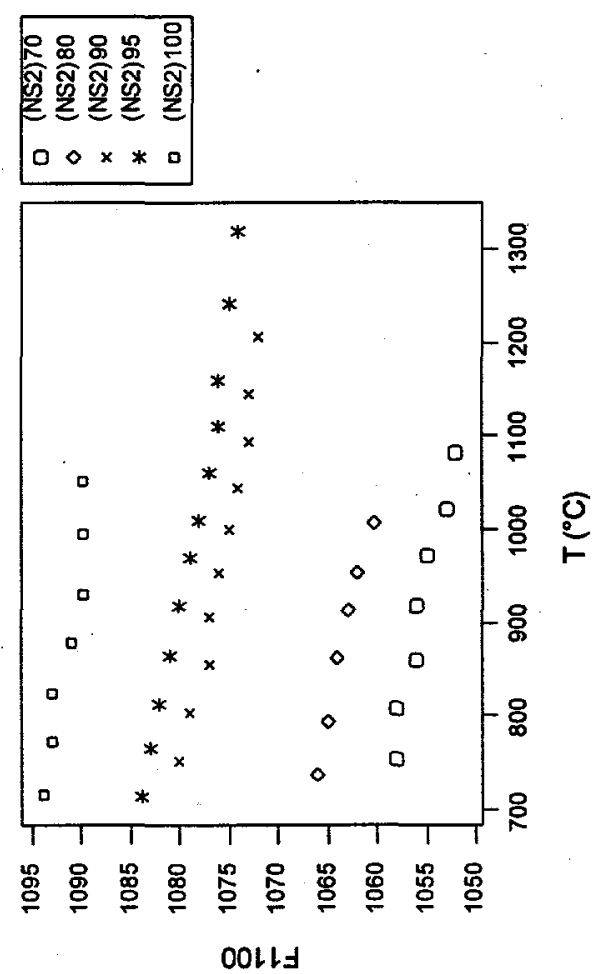

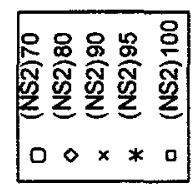

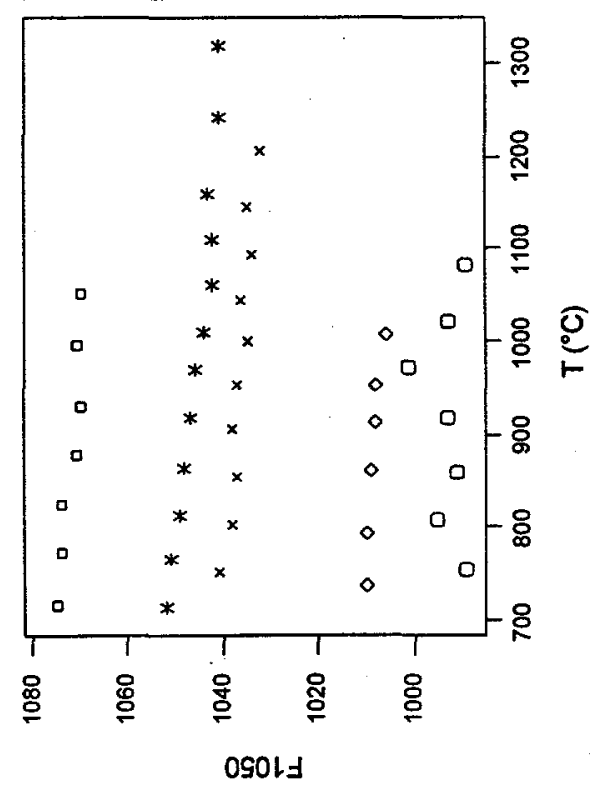



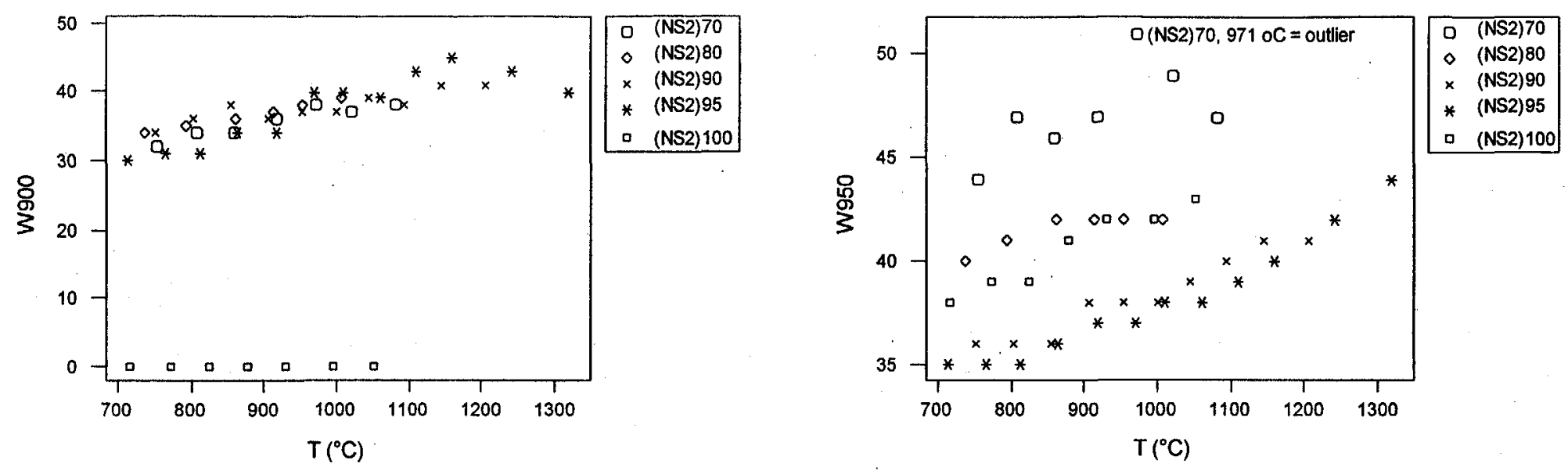

$\tilde{\omega}$
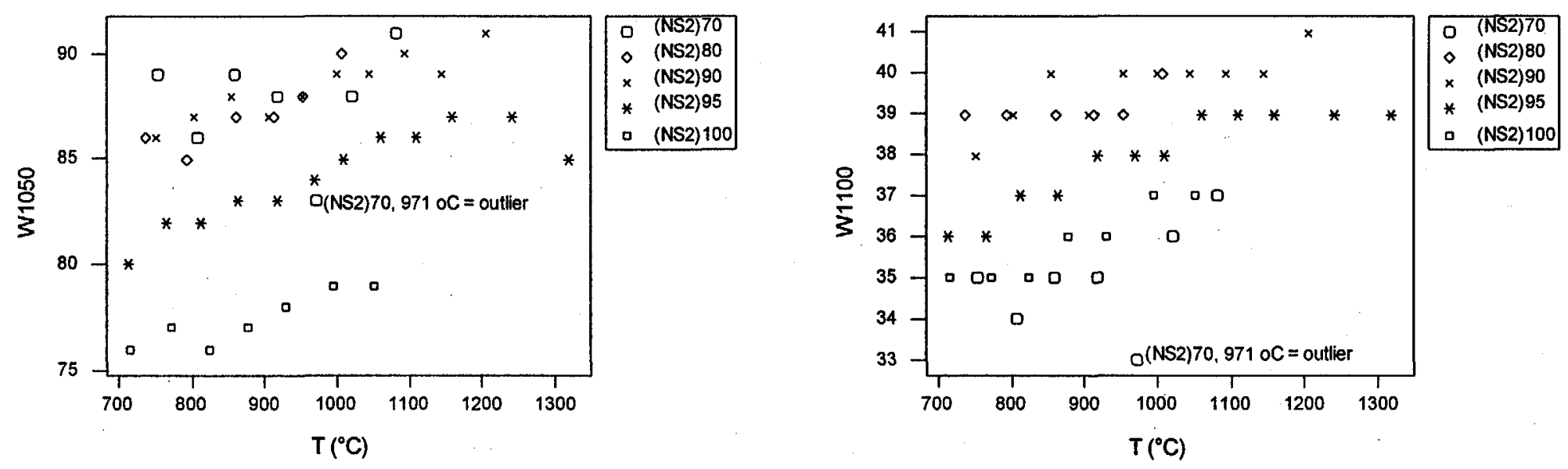

Figure C.2. Mysen and Frantz (1994b) Raman Fitted Peak Widths (FWHMs) at $900,950,1050$, and $1100 \mathrm{~cm}^{-1}$ Versus Temperature $\left({ }^{\circ} \mathrm{C}\right)$ 

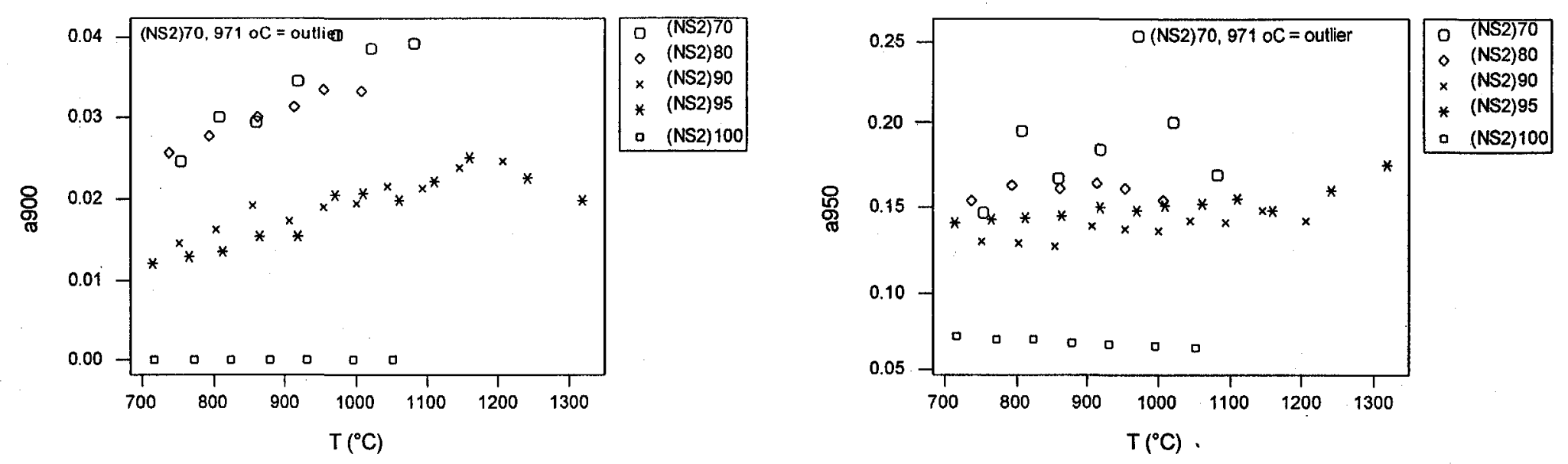

$\AA$
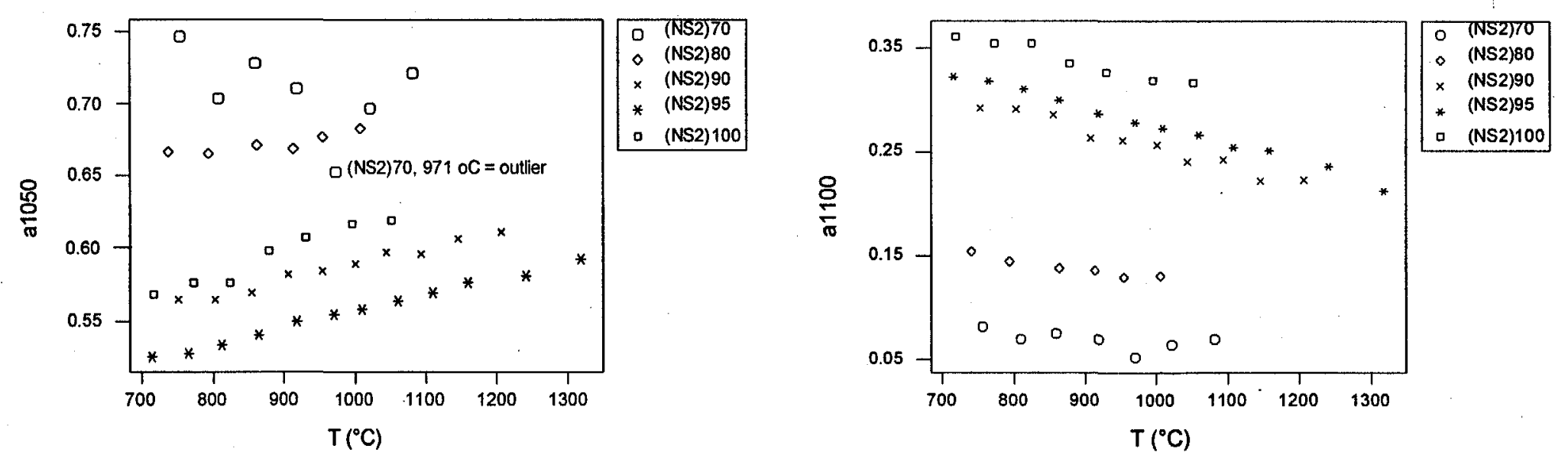

Figure C.3. Mysen and Frantz (1994b) Raman Fitted Peak Proportional Areas at $900,950,1050$, and $1100 \mathrm{~cm}^{-1}$ Versus Temperature $\left({ }^{\circ} \mathrm{C}\right)$ 


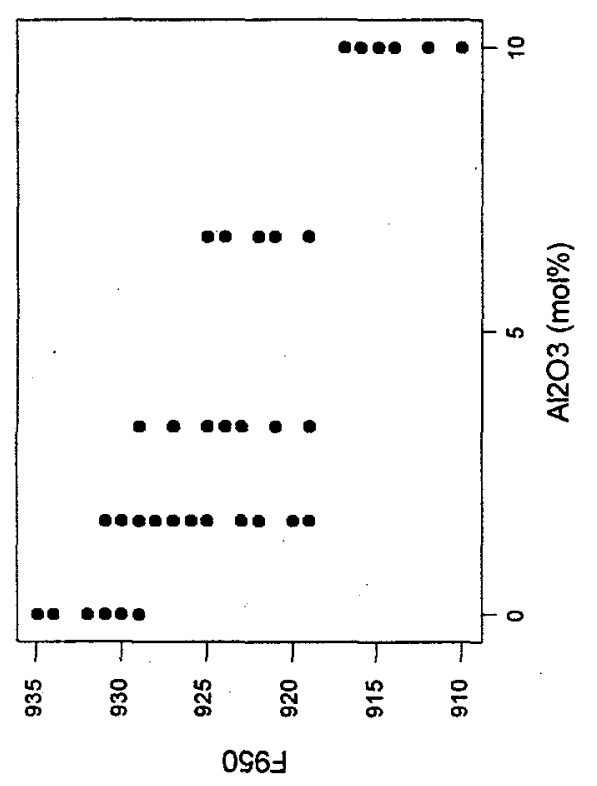

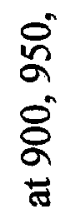

- $\frac{a}{0}$

过

总

छै

20

용

浔

灵

$\infty$ \&

올

ภㄱ

a

을

을

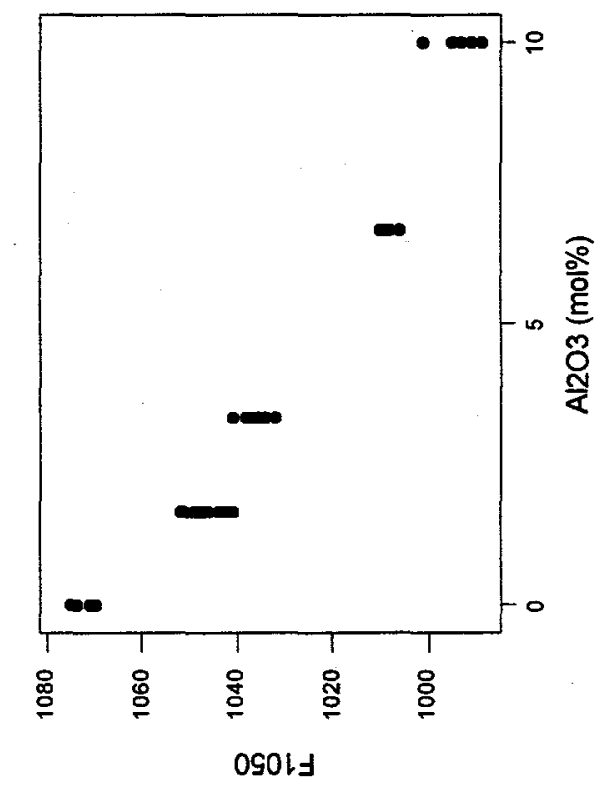

믐 물

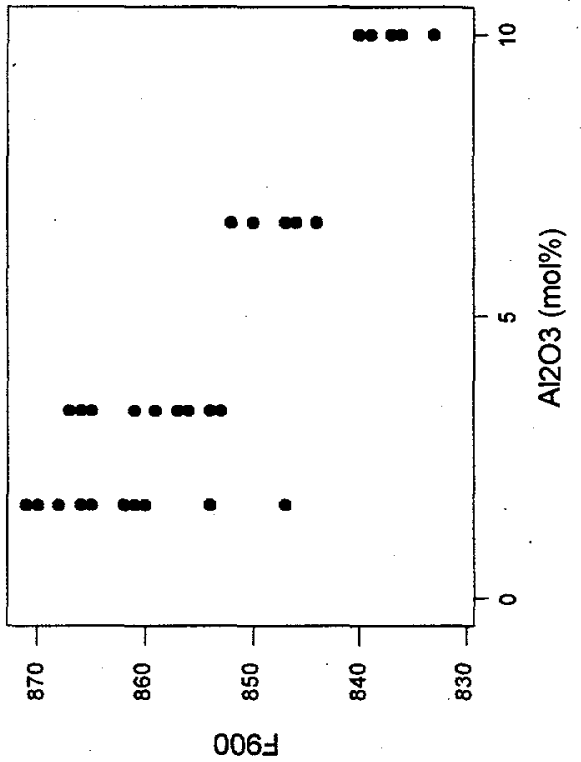

글

赵

ن

C. 5 

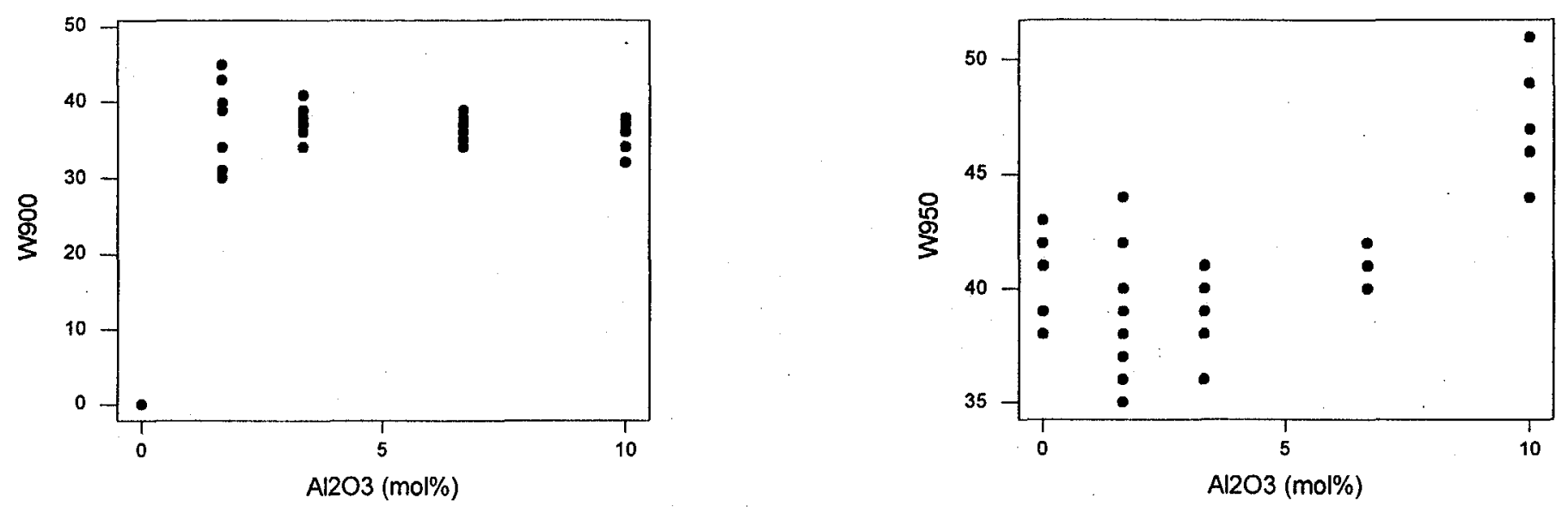

๙
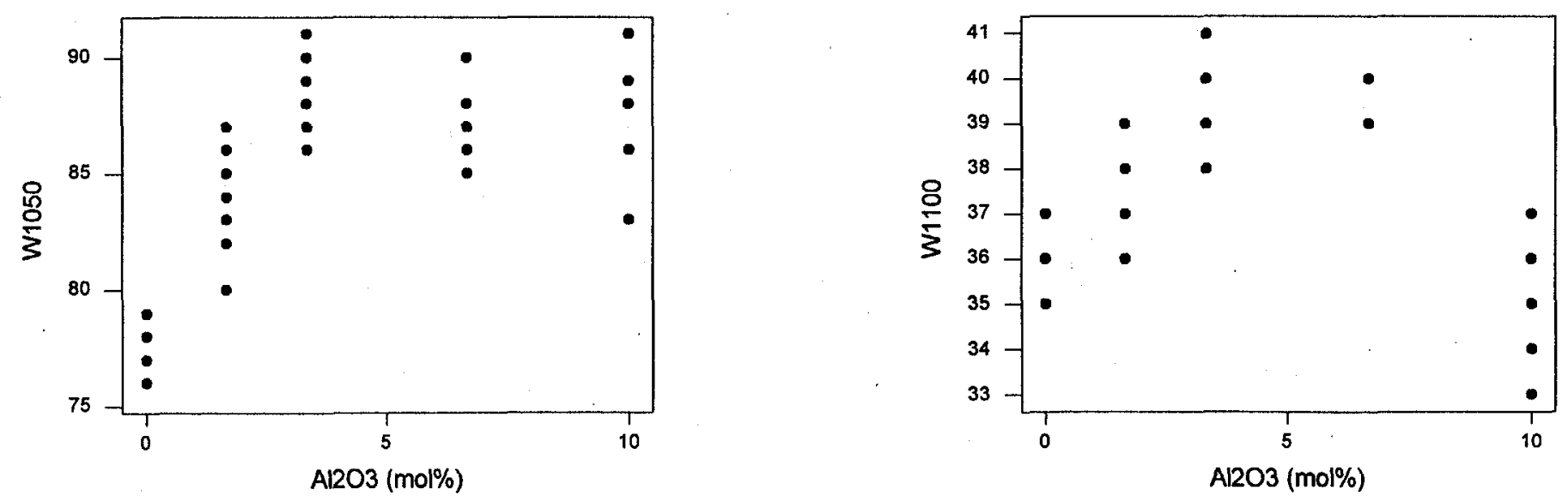

Figure C.5. Mysen and Frantz (1994b) Raman Fitted Peak Widths (FWHMs) at $900,950,1050$, and $1100 \mathrm{~cm}^{-1}$ Versus $\mathrm{Al}_{2} \mathrm{O}_{3}(\mathrm{~mol} \%)$ 

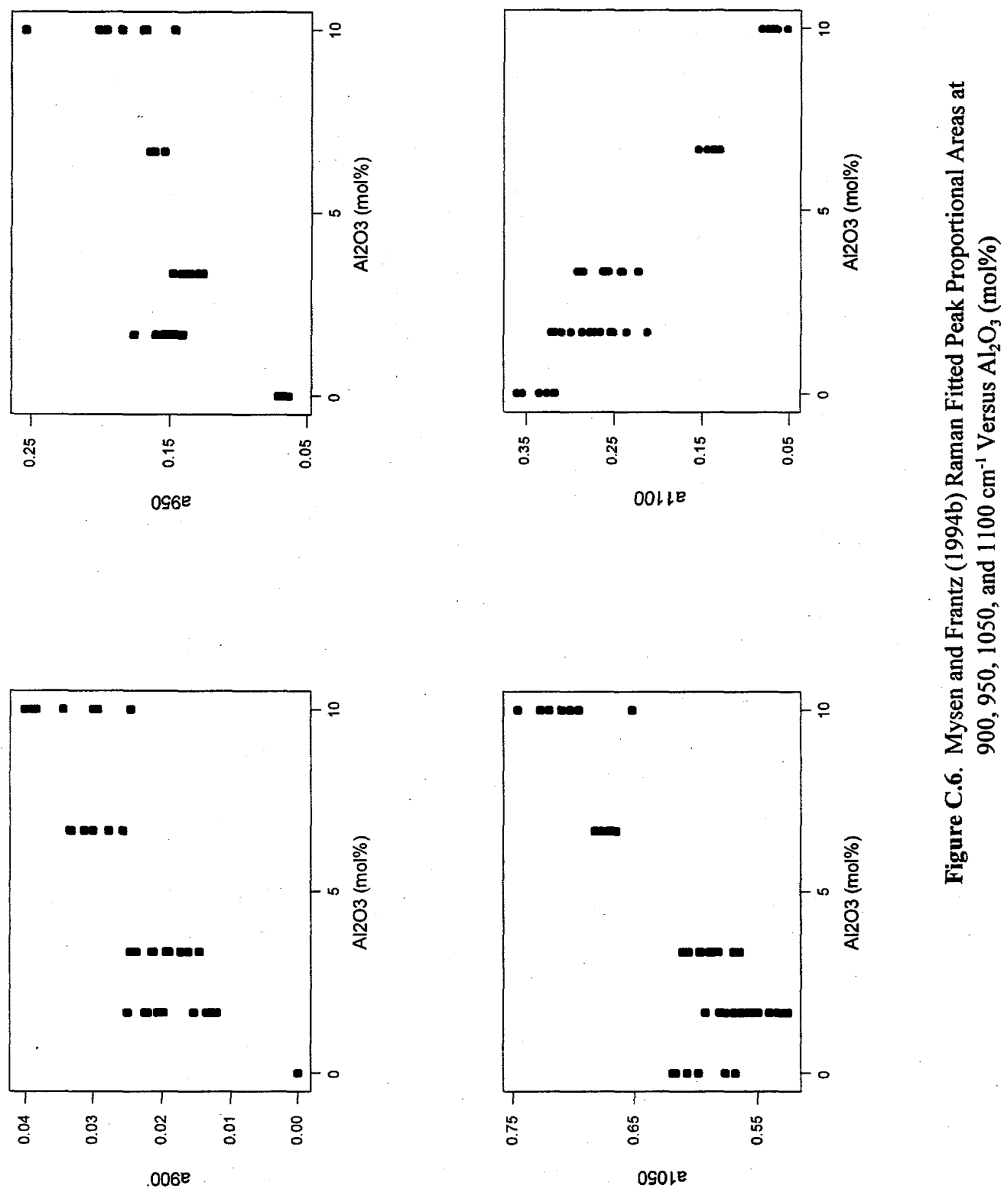

C. 7 